This document is the accepted manuscript version of the following article: Fu, F., Feurer, T., Weiss, T. P., Pisoni, S., Avancini, E., Andres, C., ... Tiwari, A. N. (2017). High-efficiency inverted semi-transparent planar perovskite solar cells in substrate configuration. Nature Energy, 2, 16190 (9 pp.). http://doi.org/10.1038/nenergy.2016.190

\title{
High-efficiency Inverted Semi-transparent Planar Perovskite Solar Cells in Substrate Configuration
}

Fan Fu*, Thomas Feurer, Thomas Paul Weiss, Stefano Pisoni, Enrico Avancini, Christian Andres, Stephan Buecheler*, and Ayodhya N. Tiwari

Laboratory for Thin Films and Photovoltaics, Empa - Swiss Federal Laboratories for Materials Science and Technology, Ueberlandstrasse 129, 8600 Duebendorf, Switzerland

*E-mail: Fan.Fu@empa.ch, Stephan.Buecheler@empa.ch

\begin{abstract}
The ability to grow perovskite solar cells in substrate configuration, where light enters the devices from the film side, allows the use of non-transparent flexible polymer and metal substrates. Furthermore, this configuration could facilitate processing directly on $\mathrm{Cu}(\mathrm{In}, \mathrm{Ga}) \mathrm{Se}_{2}$ solar cells to realize ultra-high efficiency polycrystalline all-thin-film tandem devices. However, the inversion of conventional superstrate architecture imposes severe constraints on device processing and limits the electronic quality of the absorber and charge selective contacts. Here we report a device architecture which allows inverted semi-transparent planar perovskite solar cells with a high open-circuit voltage of $1.116 \mathrm{~V}$ and substantially improved efficiency of $16.1 \%$. The substrate configuration perovskite devices show a temperature coefficient of $0.18 \% /{ }^{\circ} \mathrm{C}$ and promising thermal- and photo-stability. Importantly, the device exhibits a high average transmittance of $80.4 \%$ between $800-1200 \mathrm{~nm}$, which allows us to demonstrate polycrystalline all-thin-film tandem devices with efficiencies of $22.1 \%$ and $20.9 \%$ for $\mathrm{Cu}(\mathrm{In}, \mathrm{Ga}) \mathrm{Se}_{2}$ and $\mathrm{CuInSe} \mathrm{S}_{2}$ bottom cell, respectively.
\end{abstract}


Currently, all perovskite solar cells with efficiencies above $20 \%^{[1-7]}$ are realized in superstrate configuration (Fig. 1a) ${ }^{[8]}$, which means that the light enters the cells through the substrate. This limits the choice of substrate to transparent materials. In contrast, the substrate configuration (Fig.1b), where light enters the cell from the opposite side of the substrate (film side) ${ }^{[8]}$, allows novel device structure design since the perovskite solar cells can be grown on substrates such as flexible polymer films ${ }^{[9-10]}$, stainless steel ${ }^{[11]}$ and other metal foils ${ }^{[12]}$. Using flexible substrates permits roll-to-roll manufacturing, which is expected to lower the production cost considerably ${ }^{[13-14]}$. Moreover, the perovskite photovoltaic technology developed in substrate configuration can be directly transferred onto a $\mathrm{Cu}(\mathrm{In}, \mathrm{Ga}) \mathrm{Se}_{2}$ (CIGS) or crystallineSi solar cells stack to realize ultra-high efficiency tandem devices ${ }^{[15-18]}$. Particularly, polycrystalline all-thin-film tandem solar cells comprising a perovskite top cell and CIGS bottom cell hold great promise for a variety of applications, including building-integrated photovoltaics and mobile applications, since they can be manufactured on thin, light-weight, and flexible substrates in a cost-effective manner. Before such revolutions can happen, it is imperative to develop perovskite solar cells in substrate configuration with high efficiency and good stability.

Compared to conventional high performance superstrate configuration, the deposition sequence of each layer and related interfaces have to be inverted, which imposes severe restrictions on device design and processing, consequently limiting the electronic quality of the perovskite absorber and charge selective layers. The first substrate configuration perovskite solar cells were grown on flexible titanium foil using a simple one-step solution processed perovskite absorber and hand-laminated Ni-mesh transparent front contact ${ }^{[19]}$. The device showed a low fill factor $(\mathrm{FF})$ of $61 \%$ and open circuit voltage $\left(V_{\mathrm{OC}}\right)$ of $0.98 \mathrm{~V}$, which resulted in a low efficiency of $10.3 \%{ }^{[19]}$. Recently, Werner et al. pushed the efficiency up to $13 \%$ by improving the perovskite quality in n-i-p (deposition order) semi-transparent devices illuminated in substrate configuration ${ }^{[20]}$. However, these devices still suffer from pronounced para- 
sitic absorption in the 2,2',7,7'-tetrakis-(N,N'-di-p-methoxyphenylamine)-9,9'spirobifluorene (Spiro-OMeTAD) hole transporting layer (HTL), and require a certain thickness of $\mathrm{MoO}_{3}$ to alleviate the sputtering damage ${ }^{[20-21]}$. The additional $\mathrm{MoO}_{3}$ buffer layer reduced the transmittance ${ }^{[22]}$ and raised concerns on long-term stability as it can react with iodine diffusing from the perovskite absorber ${ }^{[23]}$. Hence, it is highly desirable to employ a p-i-n structure in substrate configuration in view of parasitic absorption and stability properties. More recently, Bush et al. reported inverted p-i-n semi-transparent perovskite solar cells with superior environmental and thermal stability ${ }^{[24]}$. However, the use of Poly $(3,4-$ ethylenedioxythiophene)-poly(styrenesulfonate) (PEDOT:PSS) as the HTL limited the $V_{\mathrm{OC}}$ to below $1 \mathrm{~V}$, which led to an efficiency of $11.5 \%$ illuminated in substrate configuration ${ }^{[24]}$. Most recently, Chen et al. reported a 16.5\% efficiency inverted semi-transparent perovskite solar cell using ultra-thin metal electrode in superstrate configuration; however, the cell efficiency is only $12.1 \%$ when measurend in substrate configuration due to the strong parasitic absorption of $\mathrm{Cu} / \mathrm{Au} / \mathrm{BCP}$ contacts. ${ }^{[25]}$ Moisture diffusion through the metal contacts ${ }^{[24]}$ and the diffusion of $\mathrm{Au}$ at elevated temperature ${ }^{[26]}$ will pose severe challenges to the long-term stability of the solar cells. Therefore, proper device polarity (p-i-n or n-i-p), structure design and suitable charge selective contacts and transparent electrodes as well as suitable perovskite deposition method are essential for developing high performance and stable substrate configuration perovskite solar cells.

Here we report efficient substrate configuration semi-transparent perovskite solar cells with a planar stack composed of glass substrate $/ \mathrm{In}_{2} \mathrm{O}_{3}: \mathrm{H} / \mathrm{PTAA} / \mathrm{CH}_{3} \mathrm{NH}_{3} \mathrm{PbI}_{3} / \mathrm{PCBM} / \mathrm{ZnO}$ nanoparticles/ZnO:Al/Ni-Al grid. Employing suitable front and rear transparent contacts and charge selective layers, the substrate configuration design enables us to fabricate perovskite devices with a high $V_{\mathrm{OC}}$ of $1.116 \mathrm{~V}$ and steady-state efficiency of $16.1 \%$ with negligible hysteresis. The device also demonstrates a superior temperature coefficient of $-0.18 \% /{ }^{\circ} \mathrm{C}$ in the temperature range of $25-65{ }^{\circ} \mathrm{C}$ with promising thermal- and photo-stability. Despite the high 
steady state efficiency, we observe a reversible light soaking effect and propose that photoconductivity changes in solution-processed $\mathrm{ZnO}$ nanoparticles upon illumination is responsible. Most importantly, in addition to high performance, the substrate configuration perovskite device exhibits a remarkably high average transmittance of $80.4 \%$ between $800-1200 \mathrm{~nm}$, which enables us to demonstrate polycrystalline all-thin-film device in 4-terminal tandem configuration with efficiencies of $22.1 \%$ and $20.9 \%$ for $\mathrm{Cu}(\mathrm{In}, \mathrm{Ga}) \mathrm{Se}_{2}$ and $\mathrm{CuInSe} \mathrm{I}_{2}$ bottom solar cell, respectively.

\section{Substrate configuration perovskite device architecture}

Figure 2a schematically illustrates the device architecture of substrate configuration perovskite solar cells. The multi-layer device is grown on a glass substrate coated with a highmobility $\left(>130 \mathrm{~cm}^{2} \mathrm{~V}^{-1} \mathrm{~s}^{-1}\right)$ transparent crystalline $\mathrm{In}_{2} \mathrm{O}_{3}: \mathrm{H}$ back contact, which was deposited by radio-frequency (RF) magnetron sputtering. The basic physical characteristics of $\operatorname{In}_{2} \mathrm{O}_{3}: \mathrm{H}$ films are shown in Supplementary Fig. 1. The perovskite absorber layer, grown by a modified

hybrid thermal evaporation/spin coating technique ${ }^{[22,27]}$, is sandwiched by solution processed poly[bis(4-phenyl)(2,4,6-trimethylphenyl)amine] (PTAA) hole transporting material and [6,6]-phenyl-C61-butyric acid methyl ester (PCBM)/ZnO nanoparticles bi-layer electron transporting materials. The device was completed by deposition of a $\mathrm{ZnO}: \mathrm{Al}$ front contact by RF-magnetron sputtering and $\mathrm{Ni}-\mathrm{Al}$ grid by e-beam evaporation. No anti-reflection coating is applied. The cell size is defined by mechanical scribing down to the $\operatorname{In}_{2} \mathrm{O}_{3}: \mathrm{H}$ back contact. More detailed device processing parameters can be found in Methods. We note that the glass serves as a substrate, and the device is illuminated from the film side as displayed in Fig. $2 \mathrm{~b}$. The scanning electron microscopy (SEM) image presented in Fig. 2c confirms the designed planar structure, and reveals a compact and flat perovskite layer with average grain size larger than the film thickness. As shown in Supplementary Fig. 2, the chlorobenzene vapor treatment during the thermal annealing process is critical to obtaining the compact and flat perov- 
skite absorber layer with a large average grain size. The use of PTAA and PCBM ensures an efficient charge extraction and transport. The $\mathrm{ZnO}$ nanoparticles employed here not only alleviate the sputtering damage but also provide ideal band alignment with sputtered $\mathrm{ZnO}: \mathrm{Al}$. Since both front and back contacts are highly transparent, the total transmittance through the whole device stack is remarkably high with an average value of $80.4 \%$ between $800-1200 \mathrm{~nm}$ as shown in Fig. 2d. The high near-infrared transmittance makes the device an ideal candidate as a top cell in tandem applications with CIGS bottom cells as it allows more low energy photons to pass through.

\section{Photovoltaic performance}

Figure 3 presents the photovoltaic performance of an inverted planar perovskite solar cell in substrate configuration measured under standard test condition $\left(25^{\circ} \mathrm{C}\right.$, simulated $\mathrm{AM} 1.5 \mathrm{G}$, $1000 \mathrm{~W} / \mathrm{m}^{2}$ ). The cell was not encapsulated and the measurements were done in ambient air with relative humidity of $50 \%$. As can be seen from Fig. 3a, there is negligible divergence of $J-V$ characteristics (generally referred to $J-V$ hysteresis) whether measured in forward $(-0.5 \mathrm{~V}$ to $1.2 \mathrm{~V})$ or backward $(1.2 \mathrm{~V}$ to $-0.5 \mathrm{~V})$ directions. Moreover, the $J-V$ curves measured in backward scan are almost identical regardless of the scan velocity varying from 18 to $190 \mathrm{mV}$ $\mathrm{s}^{-1}$ as shown in Fig. 3b. Maximum power point (MPP) under continuous illumination is measured to evaluate the power conversion efficiency at operating conditions. The photovoltaic parameters at MPP as a function of time are plotted in Fig. 3c. The cell reaches a steady-state $\eta$ of $16.1 \%, J_{\mathrm{MPP}}$ of $17.5 \mathrm{~mA} / \mathrm{cm}^{2}$, and $V_{\mathrm{MPP}}$ of $0.92 \mathrm{~V}$ at MPP after $80 \mathrm{~min}$ of continuous illumination. The $J-V$ characteristics of the perovskite solar cell with an area of $0.286 \mathrm{~cm}^{2}$ illuminated from the film side measured after MPP show a $V_{\mathrm{OC}}$ of $1.116 \mathrm{~V}$, a short circuit current density $(J \mathrm{sc})$ of $19.1 \mathrm{~mA} / \mathrm{cm}^{2}$, and a fill factor $(\mathrm{FF})$ of $75.4 \%$, yielding a power conversion efficiency $(\eta)$ of $16.1 \%$. The $J_{\mathrm{SC}}$ value is obtained by integrating the external quantum efficiency (EQE) spectrum over the AM1.5G photon flux as shown in Fig. 3d. If the device is illumi- 
nated from the glass side, a steady-state efficiency of $15.2 \%$ is obtained as presented in Supplementary Fig. 3.

The hole transporting layer is critical for achieving high $V_{\mathrm{OC}}$ and high performance in inverted p-i-n device structure ${ }^{[28]}$. The widely used PTAA $^{[1]}$ and Spiro-OMeTAD ${ }^{[3]}$ HTL in superstrate configuration perovskite solar cells are not suitable candidates when using volatile additive 4-tert-butylpyridine ( $t \mathrm{BP})$ and hygroscopic dopant lithium bis (trifluoromethanesulfonyl)imide (Li-TFSI) ${ }^{[29]}$, and will degrade during device processing. Previously most inverted perovskite solar cells employed PEDOT:PSS as the HTL and exhibited a $V_{\mathrm{OC}}$ less than $1 \mathrm{~V}$ due to the severe charge injection loss at PEDOT:PSS interface ${ }^{[30-32]}$. Besides, various promising HTLs, including PTAA, have also been explored to fabricate efficient inverted perovskite solar cells in superstrate configuration. ${ }^{[33]}$ Inspired by these achievements, we minimized the interfacial loss by using 2,3,5,6-Tetrafluoro-7,7,8,8-tetracyanoquinodimethane (F4-TCNQ) doped PTAA as the stable HTL, which was recently introduced by Wang et al. in superstrate configuration $^{[34]}$.

\section{Light soaking effect and current limitations}

The performance reported in the previous section was obtained after $80 \mathrm{~min}$ of white light soaking (AM1.5G one-sun) at MPP condition. The device shows a reversible light soaking effect as illustrated in Fig. 4a. On initial light exposure, $V_{\mathrm{OC}}$ of $1.097 \mathrm{~V}, J_{\mathrm{SC}}$ of $19 \mathrm{~mA} / \mathrm{cm}^{2}$, FF of $41.4 \%$, and $\eta$ of $8.6 \%$ in backward scan, and $V_{\mathrm{OC}}$ of $1.1 \mathrm{~V}, J_{\mathrm{SC}}$ of $19 \mathrm{~mA} / \mathrm{cm}^{2}, \mathrm{FF}$ of $42.3 \%$, and $\eta$ of $8.8 \%$ in forward scan are obtained. The slightly improved FF and $\eta$ in forward scan are probably due to the light exposure during the backward scan. Upon continuous light soaking, the MPP gradually increases from the initial state (refer to relaxed state) to the steady-state (refer to light soaked state) over time (Fig. 4a). After $\sim 80$ min of light soaking, the FF increases substantially while $J_{\mathrm{SC}}$ and $V_{\mathrm{OC}}$ remains unchanged, resulting in a significantly improved efficiency of $16.1 \%$. We note that $J-V$ divergence is negligible before and after 
light soaking, and the $V_{\text {MPP }}$ can reach steady-state very rapidly $(\sim 3 \mathrm{~s})$ in the light soaked state as shown in Fig. 4b. When the cell is stored in the dark, it gradually relaxes to the initial state. This process is rather slow and takes usually more than $24 \mathrm{~h}$.

To analyse the origin of the light soaking phenomenon (mainly the change of the fill factor) in our devices, dark and illuminated current-voltage characteristics were measured in the relaxed state as well as in the light soaked state from $123 \mathrm{~K}$ up to $303 \mathrm{~K}$ in steps of $10 \mathrm{~K}$ (see Supplementary Fig. 4). The measurement in the light-soaked state was done by tracking the MPP at room temperature until a steady state was achieved ( 1h light soaking at MPP). Subsequently, the sample was cooled down to low temperature $(123 \mathrm{~K})$ while keeping the illumination on. At this temperature the state of the sample is not expected to change anymore. During sample heating between different temperatures the sample was always kept under illumination. For the measurement of the relaxed state, the sample was exposed to illumination only for the time period $(<5 \mathrm{~s})$ needed to measure the illuminated $J-V$ curves.

The series resistance, $r_{\mathrm{s}}$, was extracted using the method proposed by Sites et al. ${ }^{[35]}$ and Hegedus et al. ${ }^{[36]}$ from the respective dark $J-V$ curves in the relaxed and light soaked state. The series resistance is plotted in an Arrhenius diagram in Figure 4c. For a thermally activated series resistance a straight line is expected. However, as the constant series resistance also contributes due to the device architecture, deviations from a straight line are observed. Therefore, the series resistance can be represented by equation (1)

$$
r_{\mathrm{s}}=R_{0}+c \exp \left(\theta_{\mathrm{B}} / k T\right)
$$

where $R_{0}$ denotes the constant part and the second term, the thermally activated part of the series resistance. The constant $c$ contains only weakly temperature dependent variables, $\theta_{\mathrm{B}}$ is the activation energy, $k$ the Boltzmann constant and $T$ the absolute temperature. The fits to equation (1) are shown as a dashed blue and red line for the relaxed and light soaked state, respectively, and the parameters are summarized in Supplementary Table 1. 
First we discuss the constant part of the series resistance $R_{0}$. In the relaxed state, the series resistance amounts to $9.2 \Omega \mathrm{cm}^{2}$. In the light soaked state, a significantly lower value of $2.3 \Omega \mathrm{cm}^{2}$ is obtained from the fit. The still rather large value in the light soaked state may originate from the $\operatorname{In}_{2} \mathrm{O}_{3}: \mathrm{H}$ back contact. The observed strong decrease of the temperature independent series resistance could be attributed to the $\mathrm{ZnO}$ nanoparticles. Indeed, previous studies show an illumination dependent photoconductivity of $\mathrm{ZnO}$ nanoparticles ${ }^{[37-39]}$. Replacing the solution processed $\mathrm{ZnO}$ nanoparticles with a sputtered $\mathrm{ZnO}$ layer eliminates the light soaking effect as shown in Supplementary Fig. 5. Also in this case, the device shows negligible divergence of $J-V$ characteristics if measured in forward or backward direction. However, the processing still needs further optimization in order to reach comparable device performance. We also tried $\mathrm{Al}$ doped $\mathrm{ZnO}$ nanoparticles to replace undoped $\mathrm{ZnO}$ nanoparticles, but so far we were not able to obtain satisfactory results.

The other two parameters $c$ and $\theta_{\mathrm{B}}$ describing the thermally activated part of the series resistance could be related to a barrier blocking of the injection current. The activation energy $\theta_{\mathrm{B}}$ for the light soaked measurement can be well evaluated as a clear temperature dependence is observed (see Figure 4c). However, the fitted value in the relaxed state is more difficult to determine as the overall series resistance is high due to $R_{0}$, and therefore masks the temperature dependent part. Thus, from this evaluation it is not clear yet if the barrier height changes upon illumination. Nevertheless, with the given values for $c$ and $\theta_{\mathrm{B}}$ the contribution to the series resistance at room temperature $(300 \mathrm{~K})$ due to the barrier can be evaluated to be $0.5 \Omega \mathrm{cm}^{2}$ in the light soaked state. Thus, reducing the barrier would further lower the series resistance and improve the fill factor in the light soaked state.

In contrast to the injection of carriers, there is no barrier observed for the extraction of the photogenerated charge carriers, which is shown in Fig. 4d. Plotted is an Arrhenius diagram for the $J_{\mathrm{SC}}$. Clearly, a linear decrease is observed when measuring at low temperatures, indicating a limited current transport for the photogenerated carriers. From the slope of a line- 
ar fit the activation energy of the barrier for the photogenerated carriers can be calculated to be $27 \mathrm{meV}$ and $18 \mathrm{meV}$ in the relaxed and light soaked state, respectively. As compared to the measured barrier $\theta_{\mathrm{B}}$ for the injection current (see Supplementary Table 1), a much smaller value is obtained for the photogenerated current.

\section{Thermal- and photo-stability}

Besides the conversion efficiency, the performance stability of the solar cells at operating conditions is of great importance for wide-spread applications and successful commercialization. Previously, the majority of stability investigations only reported the shelf stability of devices stored in dark conditions ${ }^{[40-42]}$, and very few studies attempted to evaluate stability under continuous illumination ${ }^{[3,43-44]}$. Moreover, even less attention has been paid to the device stability under combined illumination and temperature above $60{ }^{\circ} \mathrm{C}$ simultaneously, which resembles the real operating conditions ${ }^{[24,26,45]}$. We note that the shelf stability is not a suitable indicator to ensure a good stability under operating conditions. We observe that a cell with an initial efficiency of $15.8 \%$ shows no degradation after more than 1000 hours storage at room temperature under vacuum. Here we conducted preliminary stability tests on unencapsulated cells to investigate the thermal- and photo-stability of the substrate configuration perovskite solar cells close to operating conditions. To minimize the external influence of moisture and oxygen, all the measurements are carried out under vacuum (base pressure: $<5 \times 10^{-4} \mathrm{mbar}$ ) with controlled temperature. Illumination in this setup is provided with a halogen lamp and adjusted such that the perovskite solar cell yields the same $J_{\mathrm{SC}}$ as in standard test conditions. Previous reports showed that perovskite solar cells tend to degrade rapidly in the first 10 hours during constant illumination without intentional heating ${ }^{[3,26,46-49]}$. As can be seen from Fig. 5a, the $J_{\text {MPP }}, V_{\text {MPP }}$ and $P_{\text {MPP }}$ of a $16.1 \%$ cell are very stable without degradation during the 10 hours MPP measurement at $25^{\circ} \mathrm{C}$, suggesting a promising photo-stability of the device. The slightly lower $V_{\mathrm{MPP}}$ and $P_{\mathrm{MPP}}$ measured in this scenario is due to the spectral mismatch of 
the halogen lamp with the AM1.5G spectrum. Similar measurements were performed at $45^{\circ} \mathrm{C}$ and $65{ }^{\circ} \mathrm{C}$ substrate temperature as shown in Fig. $5 \mathrm{~b}$ and Supplementary Fig. 6, respectively. The device performance remains unchanged during continuous illumination at $45^{\circ} \mathrm{C}$ for 9 hours. At $65^{\circ} \mathrm{C}$ substrate temperature, degradation of the perovskite solar cell is observed. Specifically, after more than 60 hours stressing at $65^{\circ} \mathrm{C}$, the device power output is still above $70 \%$ of its original value. This is a very promising result considering the full area illumination on unencapsulated device in vacuum. Meanwhile, as shown in Fig. 5c, the substrate configuration perovskite solar cells exhibit a superior temperature coefficient of $-0.18 \% /{ }^{\circ} \mathrm{C}$ (temperature range: $25-65^{\circ} \mathrm{C}$, MPP measurments see Supplementary Fig. 6), which is better than reported value for perovskite solar cells ${ }^{[24]}$, and smaller compared to $\mathrm{CdTe}^{[50]}\left(-0.28 \% /{ }^{\circ} \mathrm{C}\right.$, from First Solar module) and $\mathrm{CIGS}^{[51]}\left(-0.38 \% /{ }^{\circ} \mathrm{C}\right.$, from Solibro module) thin film solar cells, and crystalline Si solar cells ${ }^{[52]}\left(-0.44 \% /{ }^{\circ} \mathrm{C}\right.$, from Trina module).

\section{Polycrystalline all-thin-film Perovskite-CIGS tandem devices}

With such high-performance semi-transparent perovskite solar cells, we demonstrate mechanically stacked perovskite-CIGS devices in 4-terminal tandem configuration. The perovskite top cell and CIGS bottom cell are individually processed and mechanically stacked together. In this case, the top cell and bottom cell are optically coupled while electrically decoupled $^{[24]}$, meaning that we can measure the efficiencies of each subcell separately. Besides the coherent merits of thin film technology, another advantage of CIGS over c-Si is that the bandgap of CIGS can be easily tuned by varying the $[\mathrm{Ga}] /([\mathrm{Ga}]+[\mathrm{In}])$ ratio in the absorber to realize current matching. Here, we demonstrate the feasibility of adjusting the current of the bottom cell by comparing two different absorbers, i.e., the state-of-the-art CIGS composition and Ga-free $\mathrm{CuInSe}$ (CIS) with bandgaps of $1.15 \mathrm{eV}$ and $1 \mathrm{eV}$, respectively. The fabrication processes of CIGS and CIS solar cells are described in detail by Chirila et al. ${ }^{[13]}$ The $J-V$ curves and EQE spectra of the perovskite top cell and CIGS bottom cell are displayed in Fig. 
6 , and the corresponding photovoltaic parameters are summarized in Table 1 . The efficiencies of the CIGS and CIS used have $19.2 \%$ and $13 \%$, respectively. Combined with the $16.1 \%$ perovskite top cell, efficiencies of $22.1 \%$ and $20.9 \%$ are measured in 4-terminal tandem configuration, as summarized in Table 1. Absolute efficiency gains of 2.9\% (CIGS bottom cell) and $4.8 \%$ (CIS bottom cell) are achieved compared to the highest efficient subcell. We note that the $J_{\mathrm{SC}}$ of CIS bottom cell already reaches a value of $15.3 \mathrm{~mA} / \mathrm{cm}^{2}$ without an anti-reflection coating. Further improved collection in the near-infrared region of the CIS cells will enable current matching monolithic tandem devices to be build without sacrificing the high energy photons in the top cell. Due to the low temperature processing of the substrate configuration inverted perovskite solar cells, directly monolithic growth on the $\mathrm{CI}(\mathrm{G}) \mathrm{S}$ bottom cells is feasible.

\section{Flexible perovskite solar cells on polyimide substrate}

The low-temperature process, reported here, for inverted substrate configuration perovskite solar cells opens new avenues for novel device structure design. High optical transmittance of the substrate material is no longer a requirement and the perovskite solar cells can be grown on flexible polymer films or metal foils. As a proof-of-concept, we fabricated planar perovskite solar cells on $50 \mu \mathrm{m}$ thick flexible polyimide film, and the results are shown in Supplementary Fig. 8-10. The flexible perovskite solar cell grown on polyimide shows a steady state efficiency of $8 \%$ (cell area: $0.293 \mathrm{~cm}^{2}$ ) under standard test condition with an antireflection coating. Intriguingly, the cell showed higher steady state efficiency of $9 \%$ at $80{ }^{\circ} \mathrm{C}$, particularly both the $V_{\mathrm{MPP}}$ and $J_{\mathrm{MPP}}$ increased as compared to values obtained at $25^{\circ} \mathrm{C}$. This could result from a barrier for photogenerated carriers due to unfavorable band alignment somewhere in the device, which needs further investigation. Most importantly, the devices demonstrated good stability at $81^{\circ} \mathrm{C}$ for 2 hours under continuous simulated AM1.5G illumination $\left(100 \mathrm{~mW} / \mathrm{cm}^{2}\right)$ as shown in Supplementary Figure 10. It is to be noted that the device 
was not encapsulated and the measurements were done in ambient air with relative humidity of $50 \%$. The observed efficiency gap for the device grown on polyimide originates most probably from handling issues during spin coating processing. Higher efficiency is expected by further optimizing the processing procedure.

\section{Conclusions}

In conclusion, we have demonstrated $16.1 \%$ efficiency inverted semi-transparent planar perovskite solar cells in substrate configuration along with $80.4 \%$ average transmittance between 800-1200 nm. The use of F4-TCNQ doped PTAA as stable hole transporting layer and $\mathrm{PCBM} / \mathrm{ZnO}$ nanoparticles as electron transporting layers enable fabrication of substrate configuration perovskite devices with negligible divergence of $J-V$ characteristics. The devices also show a superior temperature coefficient of $-0.18 \% /{ }^{\circ} \mathrm{C}$ in the temperature range of 25 $65{ }^{\circ} \mathrm{C}$ and promising thermal- and photo-stability at operating conditions. We observe a reversible light soaking effect in the high performance devices, and suggest that the illumination dependent photoconductivity of the $\mathrm{ZnO}$ nanoparticles might be responsible for this observation. By using these semi-transparent perovskite solar cells, we further demonstrated efficiencies of $22.1 \%$ and $20.9 \%$ in 4 -terminal tandem configuration together with CIGS and CIS solar cells, respectively. The absolute efficiency gains are $2.9 \%$ and $4.8 \%$ in CIGS and CIS compared to the highest efficient bottom cell in each case. The substrate configuration perovskite solar cells open new avenues for novel device structure design and have potential for ultra-high efficiency polycrystalline all-thin-film tandem devices with $\mathrm{CI}(\mathrm{G}) \mathrm{S}$ as the bottom cell. 


\section{Methods}

\section{Materials:}

$\mathrm{In}_{2} \mathrm{O}_{3}(99.99 \%)$ and $\mathrm{ZnO}(99.99 \%)$ targets were bought from Plasmaterials (US), and $\mathrm{Al}$ doped $\mathrm{ZnO}$ (containing $2 \mathrm{wt} \% \mathrm{Al}_{2} \mathrm{O}_{3}$ ) target was bought from Materion (99.995\%). PCBM ( $\left.\mathrm{PC}_{61} \mathrm{BM}, 99.5 \%\right)$ was bought from Solenne BV (Netherland). PTAA (702471 ALDRICH) and F4-TCNQ (97\%, 376779 ALDRICH) were bought from Sigma-Aldrich. $\mathrm{CH}_{3} \mathrm{NH}_{3} \mathrm{I}$ (powder, ITEM\# MS101000) and $\mathrm{PbI}_{2}$ (ultra dry, 99.999\%, metals basis) were purchased from Dyesol (Australia) and Alfa Aesar, respectively. Undoped ZnO nanoparticle ink (793361 ALDRICH, Synonym: Nanograde N-10, 2.7 wt.\% (crystalline $\mathrm{ZnO}$ dissolved in isopropanol), particle size: $10-15 \mathrm{~nm}$ ) was bought from Sigma-Aldrich. All chemicals are used as received without any further treatment for purification.

\section{Perovskite solar cell fabrication:}

Perovskite solar cells were grown on $1 \mathrm{~mm}$ thick soda lime glass (Thermo Scientific) substrates without diffusion barrier. Glass substrates were washed by hand first and then subjected to soap and de-ionized water sonification bath at $85^{\circ} \mathrm{C}$ each for $15 \mathrm{~min}$. A $360 \mathrm{~nm}$ thick $\mathrm{In}_{2} \mathrm{O}_{3}: \mathrm{H}$ transparent back contact was deposited by RF-magnetron sputtering at room temperature. Transparent glass substrates $(2.5 \mathrm{~cm} \times 2.5 \mathrm{~cm})$ coated with $\operatorname{In}_{2} \mathrm{O}_{3}: \mathrm{H}$ were annealed at $200{ }^{\circ} \mathrm{C}$ for $20 \mathrm{~min}$ in $\mathrm{N}_{2}$ filled glovebox before use. The hole transporting layer was prepared by spin coating $25 \mu \mathrm{l}$ of PTAA solution ( $5 \mathrm{mg} / \mathrm{ml}$ in toluene doped with $1 \mathrm{wt} \% \mathrm{~F} 4-\mathrm{TCNQ}$ ) at 6000 r.p.m. for 45 s, followed by thermal annealing at $105^{\circ} \mathrm{C}$ for $10 \mathrm{~min}$. Afterwards, a 200 $\mathrm{nm} \mathrm{PbI} \mathrm{I}_{2}$ compact film was thermally evaporated on rotating PTAA/ $/ \mathrm{In}_{2} \mathrm{O}_{3}: \mathrm{H} /$ glass without intentional heating. The deposition rate was controlled within 1-1.5 $\AA \mathrm{s}^{-1}$, and the deposition pressure was between $3-6 \times 10^{-8}$ mbar. After the $\mathrm{PbI}_{2}$ deposition, samples were transferred into glovebox for further processing. The perovskite layers were formed by spin coating of $\mathrm{CH}_{3} \mathrm{NH}_{3} \mathrm{I}$ (MAI) solution. Specifically, $250 \mu \mathrm{l}$ of MAI solution $(75 \mathrm{mg} / \mathrm{ml}$ in isopropanol) 
was first spread on $\mathrm{PbI}_{2}$ surface, and then wait $5 \mathrm{~s}$ before starting the rotation at 2000 r.p.m. for $45 \mathrm{~s}$. The as-deposited films were annealed at $100{ }^{\circ} \mathrm{C}$ for $60 \mathrm{~min}$ on glass petri dish on hotplate. After 5 min annealing, $10 \mu \mathrm{l}$ chlorobenzene solution was added at the inner edge of petri dish which was then covered by slightly larger petri dish lid. For electron transporting layer, $25 \mu \mathrm{PCBM}$ solution (20 mg/ml in chlorobenzene) was spin coated at 4000 r.p.m. for $45 \mathrm{~s}$ followed by $60 \mathrm{~min}$ annealing at $105^{\circ} \mathrm{C}$ covered by petri dish with presence of $10 \mu \mathrm{l}$ chlorobenzene. In addition, $25 \mu \mathrm{l}$ undoped $\mathrm{ZnO}$ nanoparticles was spin coated on top of PCBM at 4000 r.p.m. for $45 \mathrm{~s}$ to form bi-layer electron transporting materials. The $\mathrm{ZnO}$ nanoparticles were dried at $100{ }^{\circ} \mathrm{C}$ for $60 \mathrm{~s}$ to evaporate the solvent. Finally, the samples were finished with ZnO:Al front contact by RF-magnetron sputtering and $\mathrm{Ni}-\mathrm{Al}(50 \mathrm{~nm} / 4000 \mathrm{~nm})$ metallic grid by e-beam evaporation. No anti-reflection coating is applied in this study unless otherwise stated. The glass substrate is substituted by polyimide $(50 \mu \mathrm{m})$ film for flexible perovskite solar cells.

\section{Deposition of $\mathrm{In}_{2} \mathrm{O}_{3}: \mathrm{H}$ back contact:}

$\mathrm{In}_{2} \mathrm{O}_{3}: \mathrm{H}$ films were deposited in a high vacuum sputtering system (AJA Intl.) by RFmagnetron sputtering of ceramic $\operatorname{In}_{2} \mathrm{O}_{3}$ target at an applied sputter power density of 3.0 $\mathrm{W} / \mathrm{cm}^{2}$ without intentional heating of the substrate. The reactive atmosphere consisted of a gas mixture of $\mathrm{Ar}, \mathrm{O}_{2}$, and $\mathrm{H}_{2} \mathrm{O}$ at a total pressure of $0.6 \mathrm{~Pa} . \mathrm{H}_{2} \mathrm{O}$ vapor for $\mathrm{H}$ doping was injected via a needle valve with a partial pressure of $\sim 1 \times 10^{-4} \mathrm{~Pa}$. The deposition time is 180 min, which corresponds to $360 \mathrm{~nm} \operatorname{In}_{2} \mathrm{O}_{3}: \mathrm{H}$ in amorphous structure. The sheet resistance of as-deposited film is around $11 \Omega$ sq. $^{-1}$ measured by 4-probe method. The $\operatorname{In}_{2} \mathrm{O}_{3}: \mathrm{H}$ films were annealed at $200{ }^{\circ} \mathrm{C}$ for $20 \mathrm{~min}$ in $\mathrm{N}_{2}$ filled glovebox to obtain highly transparent and highmobility crystalline $\operatorname{In}_{2} \mathrm{O}_{3}: \mathrm{H}$ films.

\section{Deposition of ZnO:Al front contact:}


$\mathrm{ZnO}$ :Al layers were deposited in a high vacuum sputtering system by RF-magnetron sputtering of ceramic $\mathrm{ZnO}$ (containing $2 \mathrm{wt} \% \mathrm{Al}_{2} \mathrm{O}_{3}$ ) target. The deposition consist of a 5 min deposition ramp up from $0.6 \mathrm{~W} \mathrm{~cm}^{-2}$ to $2.5 \mathrm{~W} \mathrm{~cm}^{-2}$ and followed by $3 \times 3$ minutes at $2.5 \mathrm{~W} \mathrm{~cm}^{-2}$ under $20 \mathrm{sccm} \mathrm{Ar}$, and $0.29 \mathrm{sccm} \mathrm{Ar} / \mathrm{O}_{2}\left(3 \mathrm{~mol} \% \mathrm{O}_{2}\right)$. There is a $30 \mathrm{~min}$ waiting time during each step to minimize the temperature effect. The sheet resistance of as-deposited film on glass is around $56 \Omega \mathrm{sq}^{-1}$ measured by 4 -probe method.

\section{X-ray diffraction measurements:}

X-ray diffraction patterns were obtained in Bragg-Brentano geometry by using a X'Pert PRO $\theta-2 \theta \operatorname{scan}\left(\mathrm{Cu}-K_{\alpha 1}\right.$ radiation, $\left.\lambda=1.5406 \AA\right)$ from 10 to $60^{\circ}(2 \theta)$ with a step interval of $0.0167^{\circ}$.

\section{Scanning electron microscopy:}

The cross-sectional images of the samples were investigated with a Hitachi S-4800 Scanning Electron Microscope using $5 \mathrm{kV}$ acceleration voltage. A thin layer $(\sim 1 \mathrm{~nm})$ of $\mathrm{Pt}$ was coated on top of the samples to avoid charging effect.

\section{UV-Visible spectroscopy:}

The total transmittance $(T)$ and reflectance $(R)$ spectra were acquired using a UV-Vis-NIR spectrophotometer (Shimadzu UV-3600) equipped with an integrating sphere.

\section{Solar cell performance characterization:}

The current density-voltage characteristics of perovskite solar cells were measured using a ABA class solar simulator and Keithley 2400 source meter. The illumination intensity was calibrated to $1000 \mathrm{~W} \mathrm{~m}^{-2}$ using a certified single crystalline silicon solar cell. The substrate temperature is kept at $25^{\circ} \mathrm{C}$ using Peltier element. The $J-V$ measurements were performed in both forward (form $-0.5 \mathrm{~V}$ to $1.2 \mathrm{~V}$ ) and backward (from $1.2 \mathrm{~V}$ to $-0.5 \mathrm{~V}$ ) direction seperately without any pre-treatment (e.g.: holding at forward bias for certain time etc.). The step size is $20 \mathrm{mV}$ and the scan velocity varies from 18 to $190 \mathrm{mV} \mathrm{s}^{-1}$. The external quantum efficiency of the cells were measured with a lock-in amplifier. The probing beam was generated by a chopped white source ( $900 \mathrm{~W}$, halogen lamp, $260 \mathrm{~Hz}$ ) and a dual grating monochromator. The 
beam size was adjusted to ensure that the illumination area was fully inside the cell area. The shading effect of metallic grid was taken into account by including middle grid line into the illuminated area. A certified single crystalline silicon solar cell was used as the reference cell. White light bias was applied during the measurment with a halogen bias lamp. A spectral missmatch correction has been applied to the $J-V$ measurements based on the EQE current. The $J_{\mathrm{SC}}$ value is obtained by integrating the external quantum efficiency (EQE) spectrum over the AM1.5G photon flux and used to calculate the power conversion efficiency of the solar cells. The steady-state efficiency as a function of time was recorded using a maximum power point tracker, which adjusts the applied voltage in order to reach the maximum power point (perturb and observe algotrithm). The starting voltage is set to be $0.1 \mathrm{~V}$.

\section{4-Terminal tandem measurements:}

The efficiency of the device in 4-terminal configuration was determined as the sum of the top cell efficiency determined as described above and the bottom cell efficiency measured as follows: The perovskite top cell was stacked on top of the $\mathrm{CI}(\mathrm{G}) \mathrm{S}$ bottom cell using a laser scribed insulating mask to separate the bottom cell from the top cell. The corresponding aperture area is defined by the mask openning and is $0.213 \mathrm{~cm}^{2}$ in all measurements shown here. A schematic illustration of the measuement configuration can be found in the Supplementary Fig. 11 in reference 22. The metallic grid in top cell is also taken into account during the characterization of bottom cells. The measurements of $J-\mathrm{V}$ and EQE were carried out with the methods described above while being illuminated through the complete semitransparent perovskite top cell (including metallic grid). A spectral correction has been applied to the $J-V$ measurements based on the EQE current.

\section{Temperature dependent $J-V$ characterization:}

Temperature dependent $J$ - $V$ curves were recorded from $123 \mathrm{~K}$ up to $303 \mathrm{~K}$ in steps of $10 \mathrm{~K}$ in the dark as well as under illumination in vacuum (base pressure $<5 \times 10^{-4} \mathrm{mbar}$ ). A halogen lamp was used as light source and the illumination intensity was adjusted to yield the $J_{\mathrm{SC}}$ to 
match the value obtained under standard test condition. The measurement in the light soaked state was done by tracking the MPP at room temperature until a steady state was achieved ( $\sim$ h light soaking at MPP). Subsequently, the sample was cooled down to low temperature $(123 \mathrm{~K})$ while keeping the illumination on. During sample heating between different temperatures, the sample was always kept under illumination. For the measurement of the relaxed state, the sample was exposed to illumination only for the time period $(<5 \mathrm{~s})$ of the illuminated $J-V$ curve. Barriers for the extraction of photogenerated carriers might be present in the device structure and may limit the current flow at low temperatures. In that case the maximal current which can surpass such a barrier is proportional to $\exp \left(-E_{\mathrm{a}} / k T\right)$ (see for example Refs. 53-54]). In this work, an Arrhenius plot of the short circuit current density has been carried and the activation energy is obtained from a linear fit at low temperatures.

\section{Data availability statements}

The data that support the plots within this paper and other findings of this study are available from the corresponding author upon reasonable request. 


\section{References}

[1] Yang, W. S. et al. High-performance photovoltaic perovskite layers fabricated through intramolecular exchange. Science. 348, 1234-1237 (2016).

[2] Kim, Y. C. et al. Beneficial effects of PbI2 incorporated in organo-lead halide perovskite solar cells. Adv. Energy Mater. 6, 1502104 (2016).

[3] Saliba, M. et al. Cesium-containing triple cation perovskite solar cells: improved stability, reproducibility and high efficiency. Energy Environ. Sci. 9, 1989-1997 (2016).

[4] Saliba, M. et al. A molecularly engineered hole-transporting material for efficient perovskite solar cells. Nat. Energy. 1, 15017 (2016).

[5] Bi, D. Q. et al. Efficient luminescent solar cells based on tailored mixed-cation perovskites. Sci. $A d v$. 2, e1501170 (2016).

[6] Son, D. Y. et al. Self-formed grain boundary healing layer for highly efficient $\mathrm{CH}_{3} \mathrm{NH}_{3} \mathrm{PbI}_{3}$ perovskite solar cells. Nat. Energy. 1, 16081 (2016).

[7] Wang, Q. et al. Thin insulating tunneling contacts for efficient and water-resistant perovskite solar cells. Adv. Mater. 28, 6734-6739 (2016).

[8] McEvoy, A., Markvart, T. \& Castaner, L. Practical handbook of photovoltaics: Fundamentals and applications. ISBN: 978-1-85617-390-2.

[9] M. et al. Flexible high power-per-weight perovskite solar cells with chromium oxidemetal contacts for improved stability in air. Nat. Mater. 14, 1032-1039 (2015).

[10] Chirila, A. et al. Highly efficient $\mathrm{Cu}(\mathrm{In}, \mathrm{Ga}) \mathrm{Se}_{2}$ solar cells grown on flexible polymer films. Nat. Mater. 10, 857-861 (2011).

[11] Pianezzi, F. et al. Electronic properties of $\mathrm{Cu}(\mathrm{In}, \mathrm{Ga}) \mathrm{Se}_{2}$ solar cells on stainless steel foils without diffusion barrier. Prog. Photovolt: Res. Appl. 20, 253-259 (2012).

[12] Kranz, L. et al., Doping of polycrystalline CdTe for high-efficiency solar cells on flexible metal foil. Nat. Commun. 4, 2306 (2013). 
[13] Chirila, A. et al. Potassium-induced surface modification of $\mathrm{Cu}(\mathrm{In}, \mathrm{Ga}) \mathrm{Se}_{2}$ thin films for high-efficiency solar cells. Nat. Mater. 12, 1107-1111 (2013).

[14] Roldan-Carmona, C. et al. Flexible high efficiency perovskite solar cells. Energy Environ. Sci. 7, 994-997 (2014).

[15] Werner, J. et al. Efficient near-infrared-transparent perovskite solar cells enabling direct comparison of 4-terminal and monolithic perovskite/silicon tandem solar cells. ACS Energy Lett. 1, 474-480 (2016).

[16] McMeekin, D. P. et al. A mixed-cation lead mixed-halide perovskite absorber for tandem solar cells. Science. 351, 151-155 (2016).

[17] Albrecht, S. et al. Monolithic perovskite/silicon-heterojunction tandem solar cells processed at low temperature. Energy Environ. Sci. 9, 81-88 (2015).

[18] Bailie, C. et al. Semi-transparent perovskite solar cells for tandems with silicon and CIGS. Energy Environ. Sci. 8, 956-963 (2015).

[19] Troughton, J. et al. Highly efficient, flexible, indium-free perovskite solar cells employing metallic substrates. J. Mater. Chem. A. 3, 9141-9145 (2015).

[20] Werner, J. et al. Efficient monolithic perovskite/silicon tandem solar cells with cell area $>1 \mathrm{~cm}^{2}$. J. Phys. Chem. Lett. 7, 161-166 (2016).

[21] Kranz, L. et al. High-efficiency polycrystalline thin film tandem solar cells. J. Phys. Chem. Lett. 6, 2676-2681 (2015).

[22] Fu, F. et al. Low-temperature-processed efficient semi-transparent planar perovskite solar cells for bifacial and tandem applications. Nat. Commun. 6, 8932 (2015).

[23] Liu, P. et al. Interfacial electronic structure at the $\mathrm{CH}_{3} \mathrm{NH}_{3} \mathrm{PbI}_{3} / \mathrm{MoO}_{3}$ interface. Appl. Phys. Lett. 106, 193903 (2015).

[24] Bush, K. et al., Thermal and environmental stability of semi-transparent perovskite solar cells for tandems enabled by a solution-processed nanoparticle buffer layer and sputtered ITO electrode. Adv. Mater. 28, 3937-3943 (2016). 
[25] Bo, C. et al., Efficient semitransparent perovskite solar cells for $23.0 \%$ efficiency perovskite/silicon four-terminal tandem cells. Adv. Energy Mater. 6, 1601128 (2016).

[26] Domanski, K. et al. Not all that glitters is gold: metal-migration-induced degradation in perovskite solar cells. ASC Nano. 10, 6306-6314 (2016).

[27] Fu, F. et al. Controlled growth of $\mathrm{PbI}_{2}$ nanoplates for rapid preparation of CH3NH3PbI3 in planar perovskite solar cells. Phys. Status Solidi A. 212, 2708-2717 (2015).

[28] Yu, Z. \& Sun, L. Recent progress on hole-transporting materials for emerging organometal halide perovskite solar cells. Adv. Energy Mater. 5, 1500213 (2015).

[29] Bailie, C. et al. Melt-infitration of spiro-OMeTAD and thermal instability of solidstate dye-sensitized solar cells. Phys. Chem. Chem. Phys. 16, 4864-4870 (2014).

[30] Chiang, C. H. et al. Bulk heterojunction perovskite-PCBM solar cells with high fill factor. Nat. Photon. 10, 196-200 (2016).

[31] Nie, W. et al. High-efficiency solution-processed perovskite solar cells with millimeter-scale grains. Science. 347, 522-525 (2015).

[32] Hou, Y. et al. Overcoming the interface losses in planar heterojunction perovskitebased solar cells. Adv. Mater. 28, 5112-5120 (2016).

[33] Bi, C. et al. Non-wetting surface-driven high-aspect-ratio crystalline grain growth for efficient hybrid perovskite solar cells. Nat. Commun. 6, 7747 (2015).

[34] Wang, Q., Bi, C. \& Huang, J. Doped hole transport layer for efficiency enhancement in planar heterojunction organolead trihalide perovskite solar cells. Nano Energy. 15, 275-280 (2015).

[35] Sites, J. R. \& Mauk, P. H. Diode quality factor determination for thin-film solar cells. Solar Cells. 27, 411-417 (1989).

[36] Hegedus, S. S. \& Shafarman, W. N. Thin-film solar cells: device measurments and analysis. Prog. Photovolt: Res. Appl. 12, 155-176 (2004). 
[37] Lilliedal, M. R. et al. The effect of post-processing treatments on inflection points in current-voltage curves of roll-to-roll processed polymer photovoltaics. Solar Energy Mater. Solar Cells. 94, 2018-2031 (2010).

[38] Gurwitz, R. et al. Interaction of light with the $\mathrm{ZnO}$ surface: photon induced oxygen “breathing”, oxygen vacancies, persistent photoconductivity, and persistant photovoltage. J. Appl. Lett. 115, 033701 (2014).

[39] Chen, S. et al. Inverted polymer solar cells with reduced interface recombination. $A d v$. Energy Mater. 2, 1333-1337 (2012).

[40] Deng, Y. et al. Air-stable, efficient mixed-cation perovskite solar cells with Cu electrode by scalable fabrication of active layer. Adv. Energy Mater. 6, 1600372 (2016).

[41] Back, H. et al. Achieving long-term stable perovskite solar cells via ion neutralization. Energy Environ. Sci. 9, 1258 (2016).

[42] You, J. et al. Improved air stability of perovskite solar cells via solution-processed metal oxide transport layers. Nat. Nanotech. 11, 75-81 (2016).

[43] Mei, A. et al. A hole-conductor-free, fully printable mesoscopic perovskite solar cell with high stability. Science. 345, 295-298 (2015).

[44] Chen, W. et al. Efficient and stable large-area perovskite solar cells with inorganic charge extraction layers. Science. 350, 944-948 (2015).

[45] Li, X. et al. Outdoor performance and stability under elevated temperatures and longterm light soaking of triple-layer mesoscopic perovskite photovoltaics. Energy Techol. 3, 551-555 (2015).

[46] Lee, J. W. et al. Formamidinium and cesium hybridization for photo- and moisturestable perovskite solar cell. Adv. Energy. Mater. 5, 1501310 (2015).

[47] Bryant, D. et al. Light and oxygen induced degradation limits the operational stability of methylammonium lead triiodide perovskite solar cells. Energy Environ. Sci. 9, $1655-1660$ (2016). 
[48] Abate, A. et al. Silothiophene-linked triphenylamines as stable hole transporting materials for high efficiency perovskite solar cells. Energy Environ. Sci. 8, 2946-2953 (2015)

[49] Kulbak, M. et al. Cesium enhances long-term stability of lead bromide perovskitebased solar cells. J. Phys. Chem. Lett. 7, 167-172 (2016).

[50] First Solar Series $4^{\mathrm{TM}}$ PV Module Datasheet, March 2016. http://www.firstsolar.com//media/Documents/Module-Support/Series-4V3-Datasheet.ashx

[51] Solibro SL2 CIGS Thin-film module, Generation 2.0. http://solibrosolar.com/uploads/media/Solibro_data_sheet_SL2_G2-0_2015-09_Rev01_EN.pdf

[52] Trina solar, the module TSM-PD14, http://www.trinasolar.com/HtmlData/downloads/us/US_Datasheet_PD14.pdf

[53] Niemegeers, A. et al. On the CdS/CuInSe2 conduction band discontinuity. Appl. Phys. Lett. 67, 843 (1995).

[54] Scheer, R. \& Schock, H. W. Chalcogenide Photovoltaics: Physics, Technologies, and Thin Film Devices. WILEY-VCH Verlag GmbH \& Co. KGaA, 2011. ISBN:978-3-52731459-1. 


\section{Acknowledgements}

Financial funding from Swiss National Science Foundation (SNF)-NRP70, PV2050 (project NO.: 407040_153976 and 407040_153916), SNF-NanoTera and Swiss Federal Office of Energy (SYNERGY: 20NA21_150950), as well as Competence Center for Energy and Mobility are gratefully acknowledged. F.F. thanks the financial support from the Chinese Scholarship Council (CSC).

\section{Contributions}

F.F., S.B., and A.N.T designed the research and experiments. F.F., T.F., and A.E. fabricated the perovskite solar cells and CIGS solar cells. F.F., T.F., T.P.W., S.P., E.A., C.A, S.B., and A.N.T performed the characterization and analysis. F.F., S.B., and A.N.T. wrote the paper. All authors contributed to discussions.

\section{Competing interests}

The authors declare no competing financial interests.

\section{Corresponding authors}

Correspondence to Fan Fu or Stephan Buecheler.

\section{Additional information}

Supplementary information is available in the online version of the paper. Correspondence and requests for materials should be addressed to F.F. or S.B. 


\section{Figures and tables}

Figure 1. Perovskite solar cell configurations. a, b, Schematic of a perovskite solar cell in the conventional superstrate configuration (a) and the substrate configuration (b). The arrows represent the light illumination direction. The ETM and HTM stands for electron transport material and hole transport material, respectively.

a

\section{superstrate configuration}

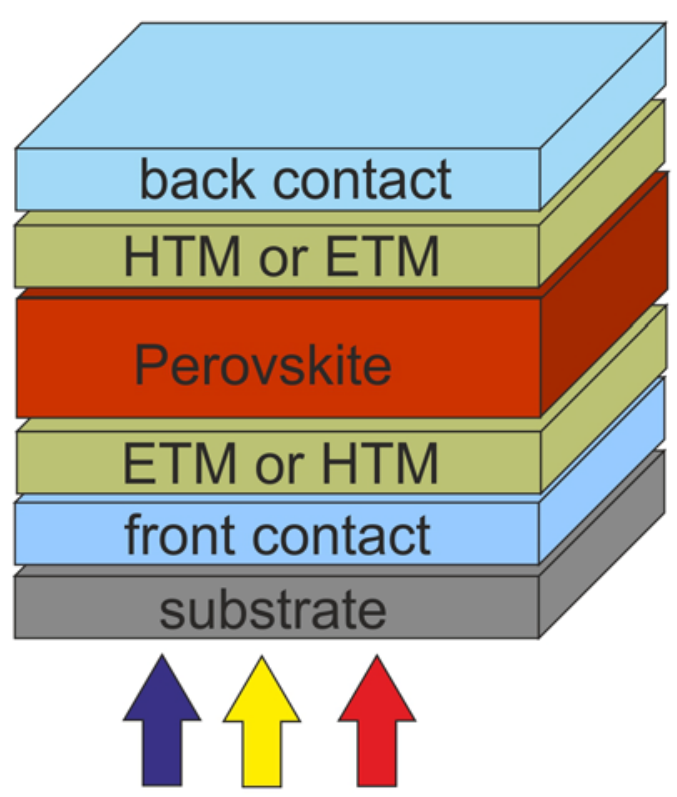

light b

\section{substrate} configuration

light

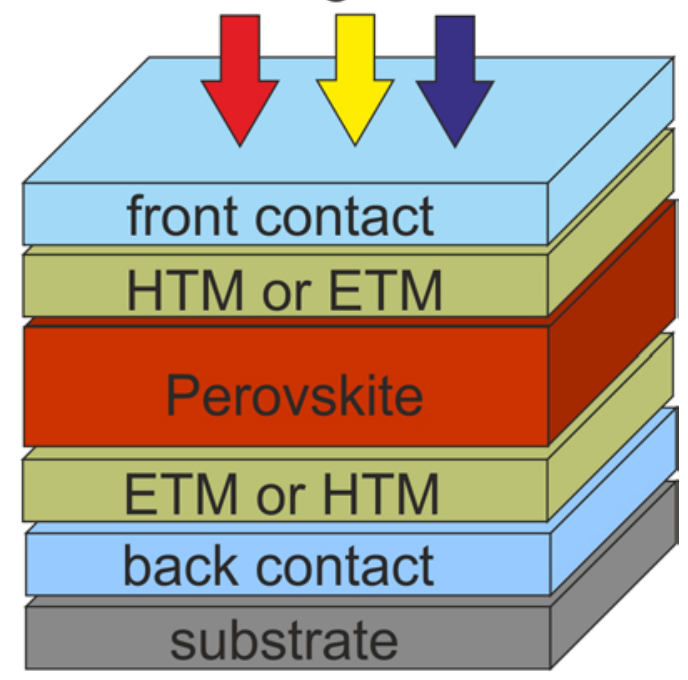


Figure 2. Inverted semi-transparent planar perovskite solar cells in substrate configuration. a, b, c, The schematic illustration (a), photograph (b), and SEM micrograph (c) of substrate configuration planar perovskite solar cells grown on glass substrate. The arrows in Fig. $2 \mathrm{a}$ represent the light illumination direction. The substrate size shown in Fig. $2 b$ is $2.5 \times 2.5$ $\mathrm{cm}^{2}$. d, The transmittance throught the whole device stack. The average transmittance is $80.4 \%$ between 800 to $1200 \mathrm{~nm}$.
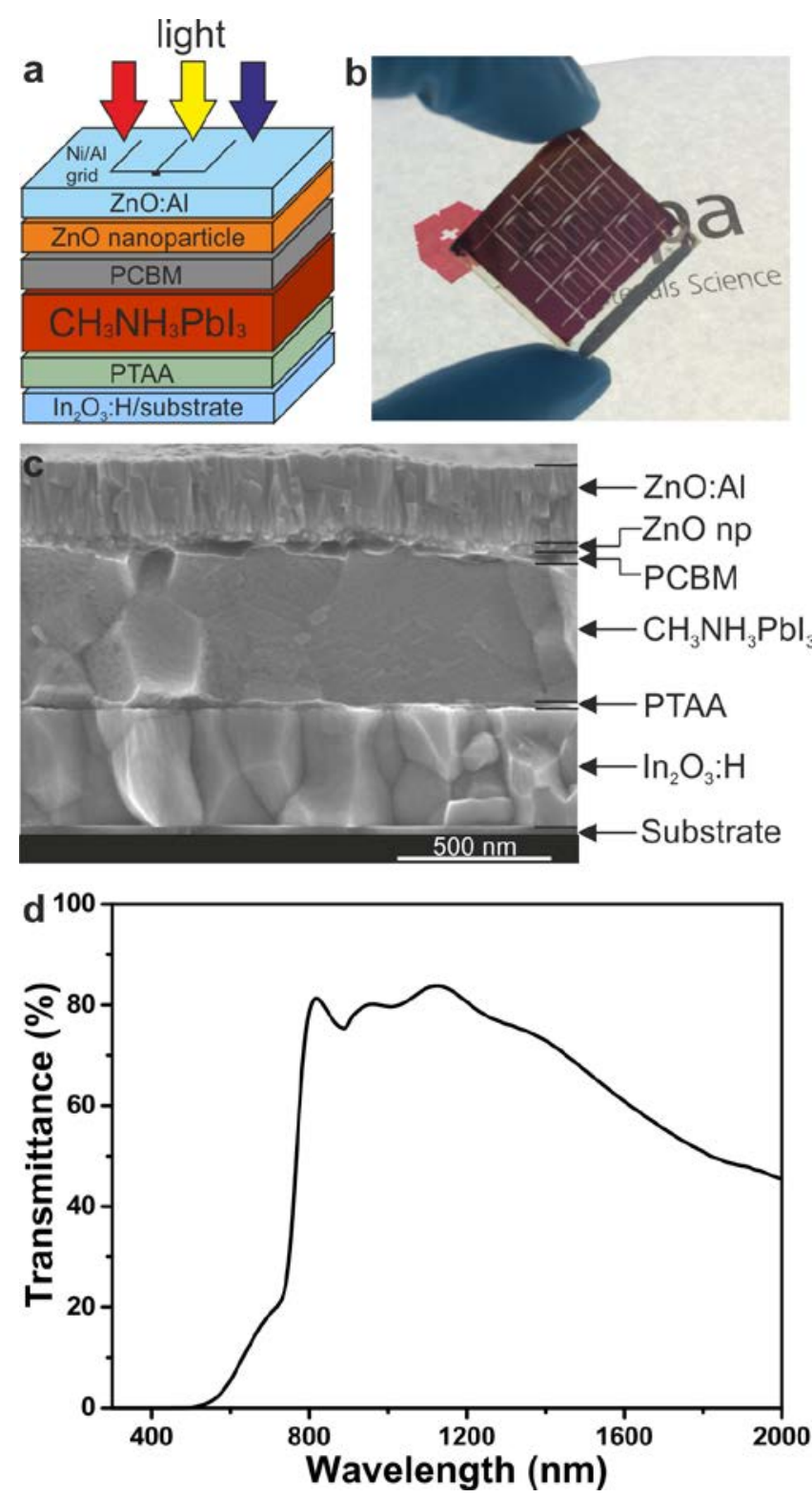
Figure 3 | Photovoltaic performance characterizations. a, The current density-voltage $(J-V)$ curves in forward $(-0.5 \mathrm{~V}$ to $1.2 \mathrm{~V})$ and backward scan $(1.2 \mathrm{~V}$ to $-0.5 \mathrm{~V})$ with $20 \mathrm{mV}$ step size and scan velocity: $190 \mathrm{mV} \mathrm{s}^{-1}$ measured under standard test condition $\left(25^{\circ} \mathrm{C}\right.$, simulated

AM1.5G, $1000 \mathrm{~W} / \mathrm{m}^{2}$ ). The device was light soaked at maximum power point (MPP) for 80 min prior to measurements. $\mathbf{b}$, The $J-V$ curves in backward scan direction with different scan velocity varying from 18 to $190 \mathrm{mV} \mathrm{s}^{-1}$. c, The steady-state output at maximum power point of the corresponding cell under continuous simulated AM1.5G one sun illumination. $\mathbf{d}$, The external quantum efficiency $(\mathrm{EQE})$ spectum. The calculated $J_{\mathrm{SC}}$ from EQE curve is 19.1 $\mathrm{mA} / \mathrm{cm}^{2}$. It is to be noted that the device was not encapsulated and all the measurements were performed in ambient air with relative humidity of 50\%. No anti-reflection coating is applied.
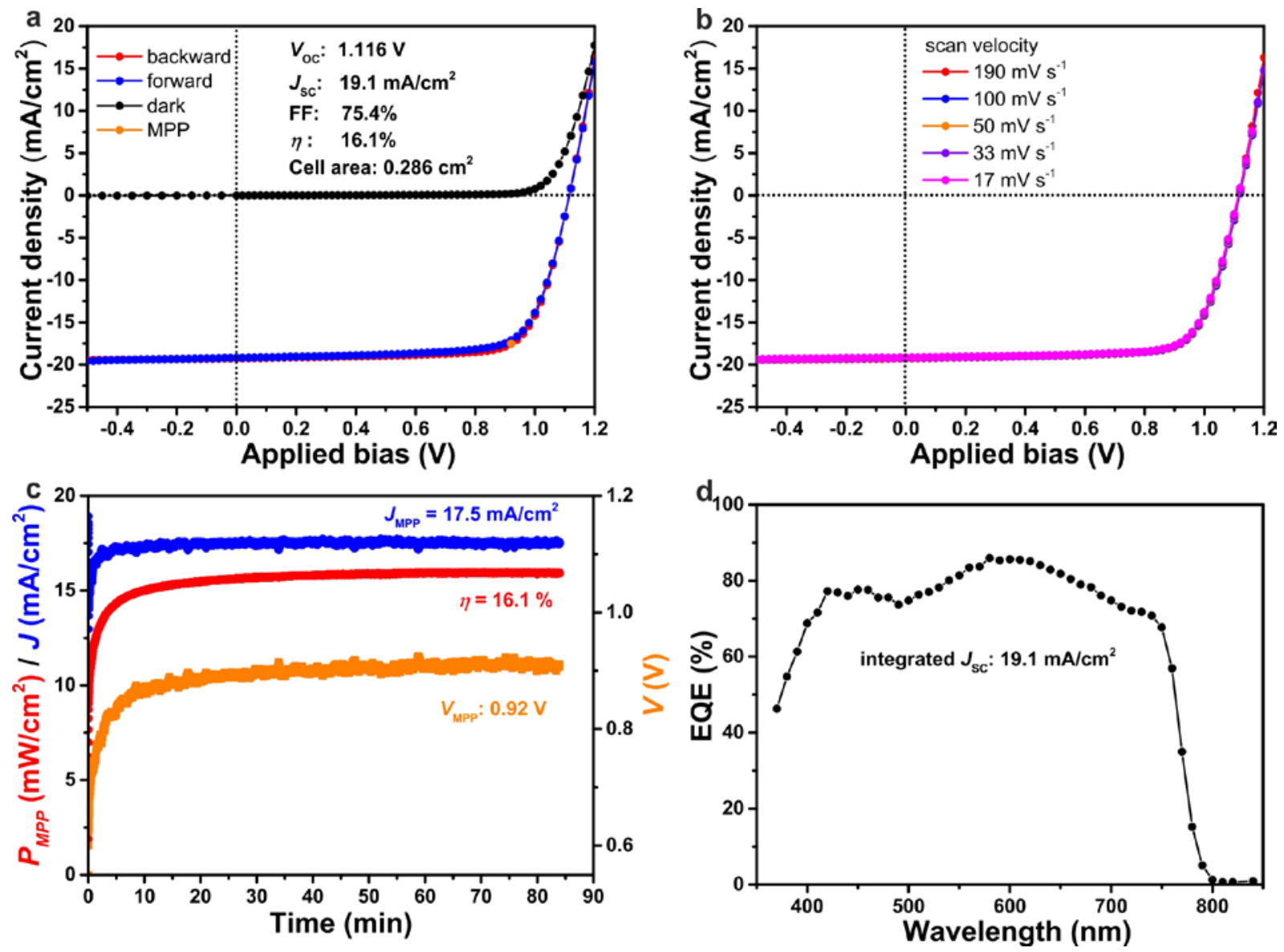
Figure 4. Light soaking effect. a, The reversible light soaking effect of the device shown in Fig. 3. The device state before and after the light soaking treatment at MPP were referred to relaxed state and light soaked state, respectively. $\mathbf{b}$, The comparison of $V_{\text {MPP }}$ transient for the relaxed state and light soaked state. c, d, The Arrhenius plot of the series resistance $r_{\mathrm{S}}(\mathbf{c})$ and $J_{\mathrm{SC}}(\mathbf{d})$ for the relaxed state and light soaked state. The fits in Fig. $4 \mathrm{c}$ is based on equation (1) and the fits in Fig. 4d is decribed in more detail in Methods.
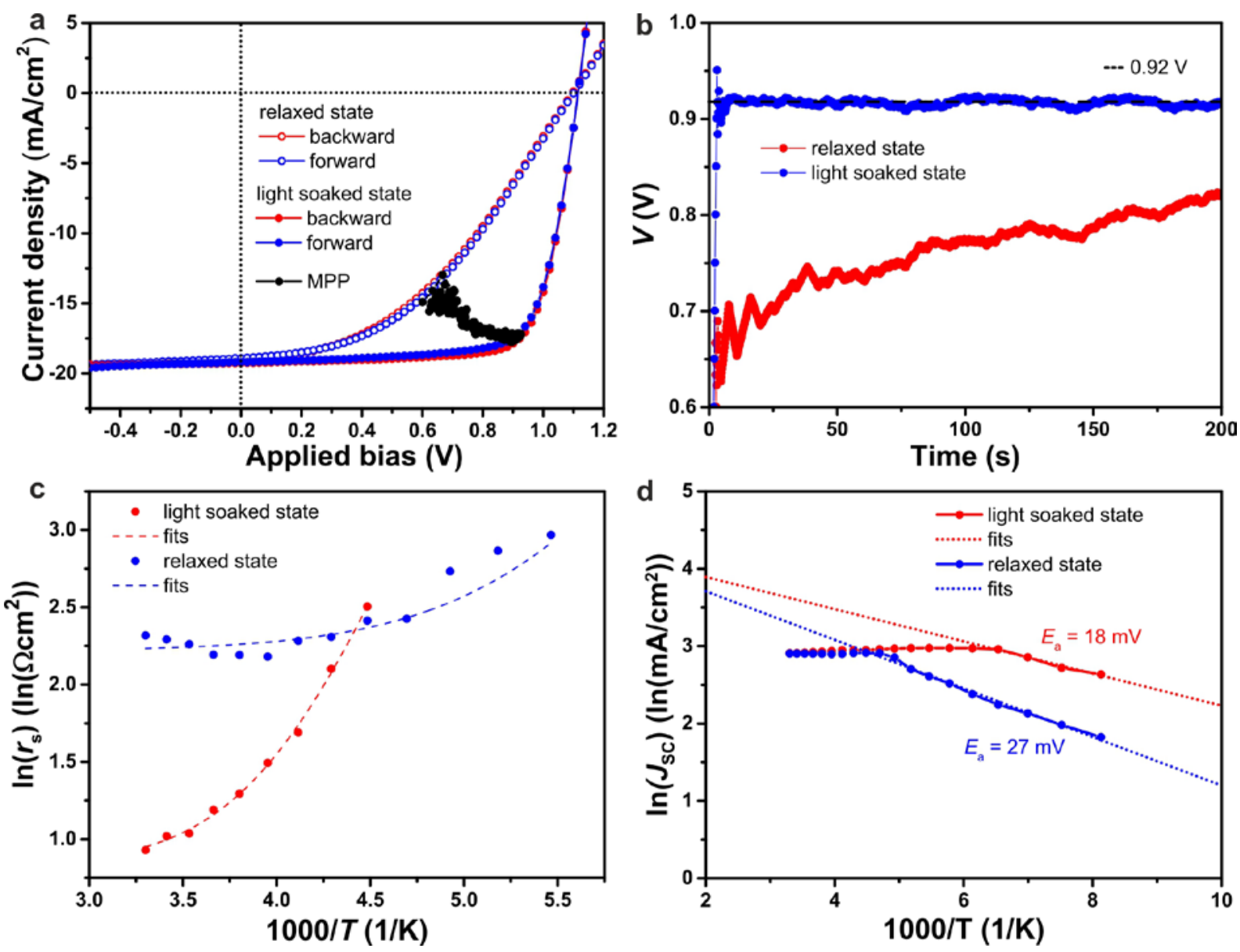
Figure 5. Thermal- and photo-stability. a, b, The maximum power point measurements for the substrate configuration perovskite solar cell (initial efficiency of $16.1 \%$ under standard test conditions (STC)) on $25{ }^{\circ} \mathrm{C}(\mathbf{a}), 45^{\circ} \mathrm{C}$ (b) substrate temperature. c, The temperature coefficient of substrate configuration perovskite solar cell (initial efficiency of $15.3 \%$ under STC) in temperature range between $25-65^{\circ} \mathrm{C}$. A linear fits (dashed line) is used to guide the eyes. The devices were not encapsulated and the measurements were done in cryostat chamber under vacuum (base pressure $<5 \times 10^{-4} \mathrm{mbar}$ ) with full area one-sun illumination. A halogen lamp is used as light source and the intensity is adjusted to be one sun. An $3 \mathrm{~mm}$ fluorinedoped tin oxide (FTO, TEC-15) coated glass is put in front of the light source to minimize the heating effect from infrared light. We note that the $V_{\mathrm{OC}}$ and $\mathrm{FF}$ values measured in cryostat chamber are lower than that measured under STC.
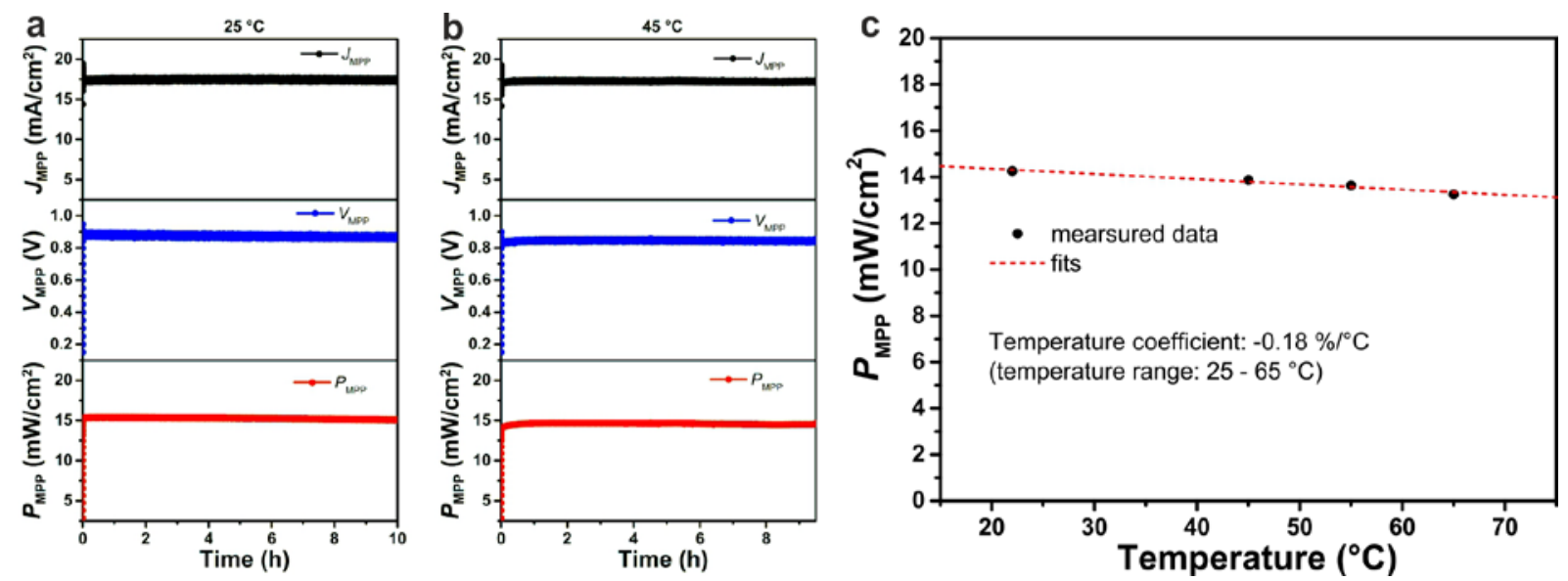
Figure 6. Polycrystalline all-thin-film perovskite-CIGS 4-terminal tandem solar cell. a, b, the current density-voltage curves (a) and EQE spectra (b) of the perovskite-CIGS in 4terminal tandem configuration. c, d, the current density-voltage curves (c) and EQE spectra (d) of the perovskite-CIS in 4-terminal tandem configuration.
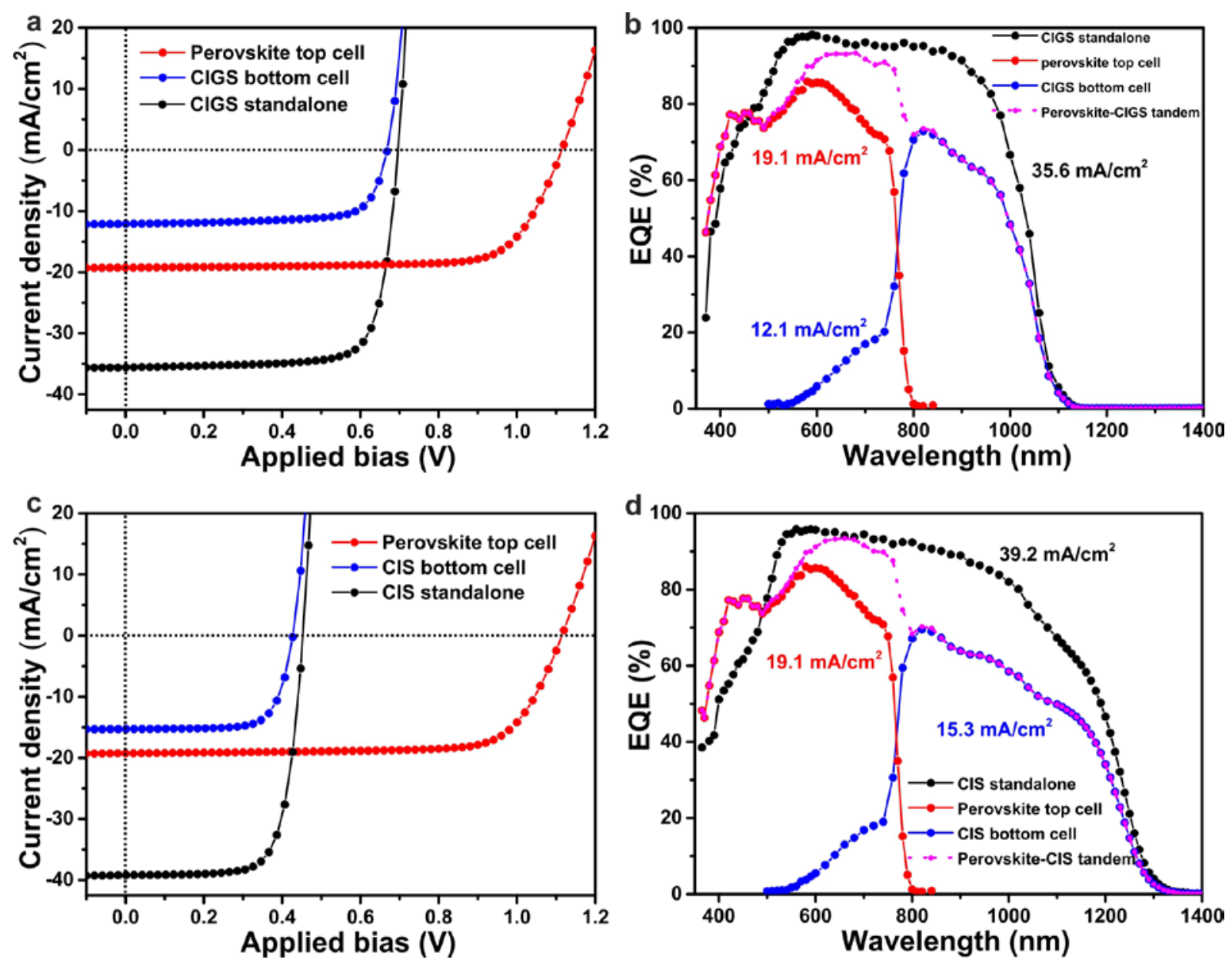
Table 1 | Photovoltaic parameters of the polycrystalline all-thin-film perovskite-CIGS solar cells in 4-terminal tandem configuration. Absolute efficiency gains of $2.9 \%$ (CIGS) and $4.8 \%$ (CIS) are achieved compared to the highest efficient subcell. ( $J_{\mathrm{SC}}$ values were integrated from EQE spectra and then used to calculate the power conversion efficiencies for all solar cells shown below.)

\begin{tabular}{|c|c|c|c|c|c|c|}
\hline Solar cell & $\begin{array}{l}V_{\mathrm{OC}} \\
(\mathrm{V})\end{array}$ & $\begin{array}{l}J_{\mathrm{SC}}(\mathrm{EQE}) \\
\left(\mathrm{mA} / \mathrm{cm}^{2}\right)\end{array}$ & $\begin{array}{l}F F \\
(\%)\end{array}$ & $\begin{array}{c}\eta \\
(\%)\end{array}$ & $\begin{array}{l}\text { MPP } \\
(\%)\end{array}$ & $\begin{array}{c}\text { Cell area } \\
\left(\mathrm{cm}^{2}\right)\end{array}$ \\
\hline Perovskite top cell & 1.116 & 19.1 & 75.4 & 16.1 & 16.1 & 0.286 \\
\hline CIGS (standalone) & 0.696 & 35.6 & 77.3 & 19.2 & 19.2 & 0.213 \\
\hline CIGS bottom cell & 0.669 & 12.1 & 73.6 & 6.0 & 6.0 & 0.213 \\
\hline $\begin{array}{l}\text { Perovskite-CIGS } \\
\text { 4-terminal tandem }\end{array}$ & & & & & 22.1 & \\
\hline CIS (standalone) & 0.453 & 39.2 & 73.1 & 13.0 & 13.0 & 0.213 \\
\hline CIS bottom cell & 0.428 & 15.3 & 73.1 & 4.8 & 4.8 & 0.213 \\
\hline $\begin{array}{l}\text { Perovskite-CIS } \\
\text { 4-terminal tandem }\end{array}$ & & & & & 20.9 & \\
\hline
\end{tabular}


Supplementary information

\section{High-efficiency Inverted Semi-transparent Planar Perovskite Solar Cells in Substrate Configuration}

Fan Fu*, Thomas Feurer, Thomas Paul Weiss, Stefano Pisoni, Enrico Avancini, Christian Andres, Stephan Buecheler*, and Ayodhya N. Tiwari

Laboratory for Thin Films and Photovoltaics, Empa - Swiss Federal Laboratories for Materials Science and Technology, Ueberlandstrasse 129, 8600 Duebendorf, Switzerland

* E-mail: Fan.Fu@empa.ch, Stephan.Buecheler@empa.ch 

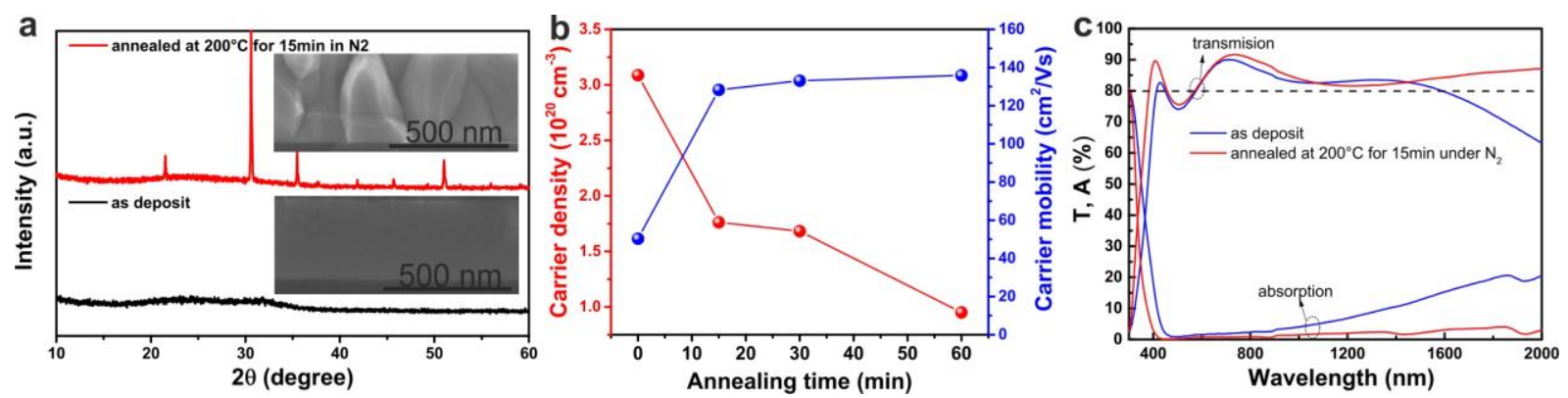

Supplementary Figure 1. Physical properties of $\operatorname{In}_{2} \mathbf{O}_{3}: \mathbf{H}$ films. a, The SEM and X-ray diffraction (XRD) patterns of $\operatorname{In}_{2} \mathrm{O}_{3}: \mathrm{H}$ film before and after thermal annealing treatment. $\mathbf{b}, \mathrm{An}-$ nealing time dependent carrier density and carrier mobility of $\operatorname{In}_{2} \mathrm{O}_{3}: \mathrm{H}$ films. c, The transmission and absorption of $\operatorname{In}_{2} \mathrm{O}_{3}: \mathrm{H}$ film on glass substrate. 

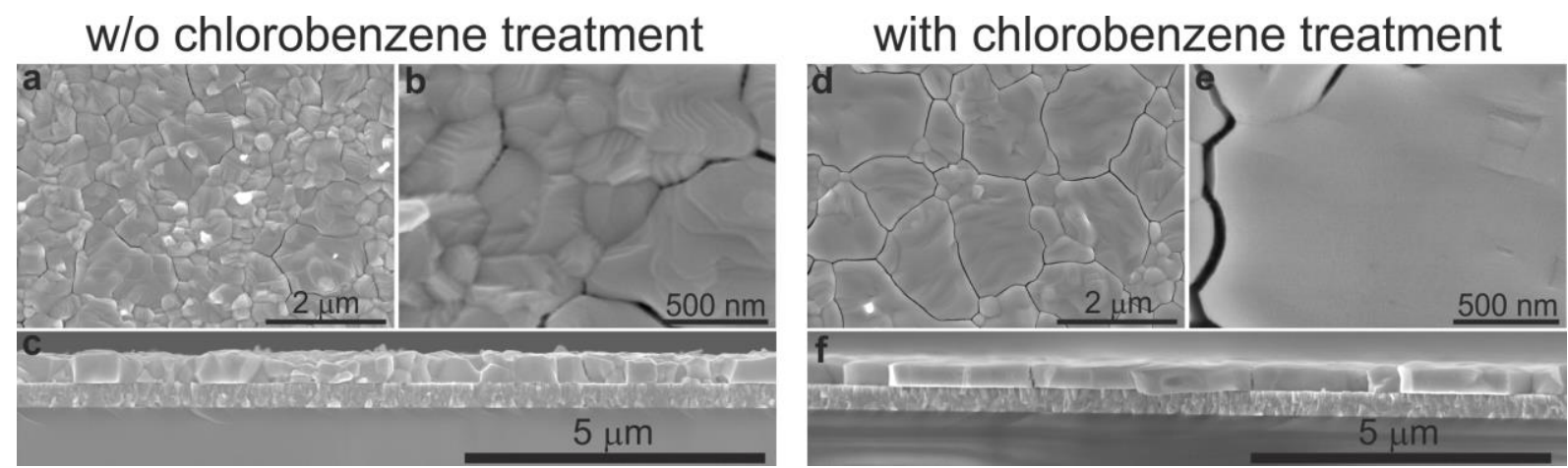

Supplementary Figure 2. The effect of chlorobenzene vapor treatment on perovskite morphology. a, b, c, The top view $(\mathbf{a}, \mathbf{b})$ and cross-section (c) SEM images of perovskite absorber without chlorobenzene vapor treatment. The average grain size is small, and the perovskite surface is very rough with terrace-like texture. $\mathbf{d}, \mathbf{e}, \mathbf{f}$, The top view $(\mathbf{d}, \mathbf{e})$ and crosssection (f) SEM images of perovskite absorber with chlorobenzene vapor treatment. The average grain size increased significantly and the surface became much more even after the chlorobenzene vapor treatment. It is to be noted that the $\mathrm{PbI}_{2}$ films are evaporated in the same run, and all other processing conditions are same except for the chlorobenzene vapor treatment during thermal annealing at $100^{\circ} \mathrm{C}$ for $60 \mathrm{~min}$. The observed wide grain boundaries originate from the electron beam induced decomposition of the perovskite crystals. 

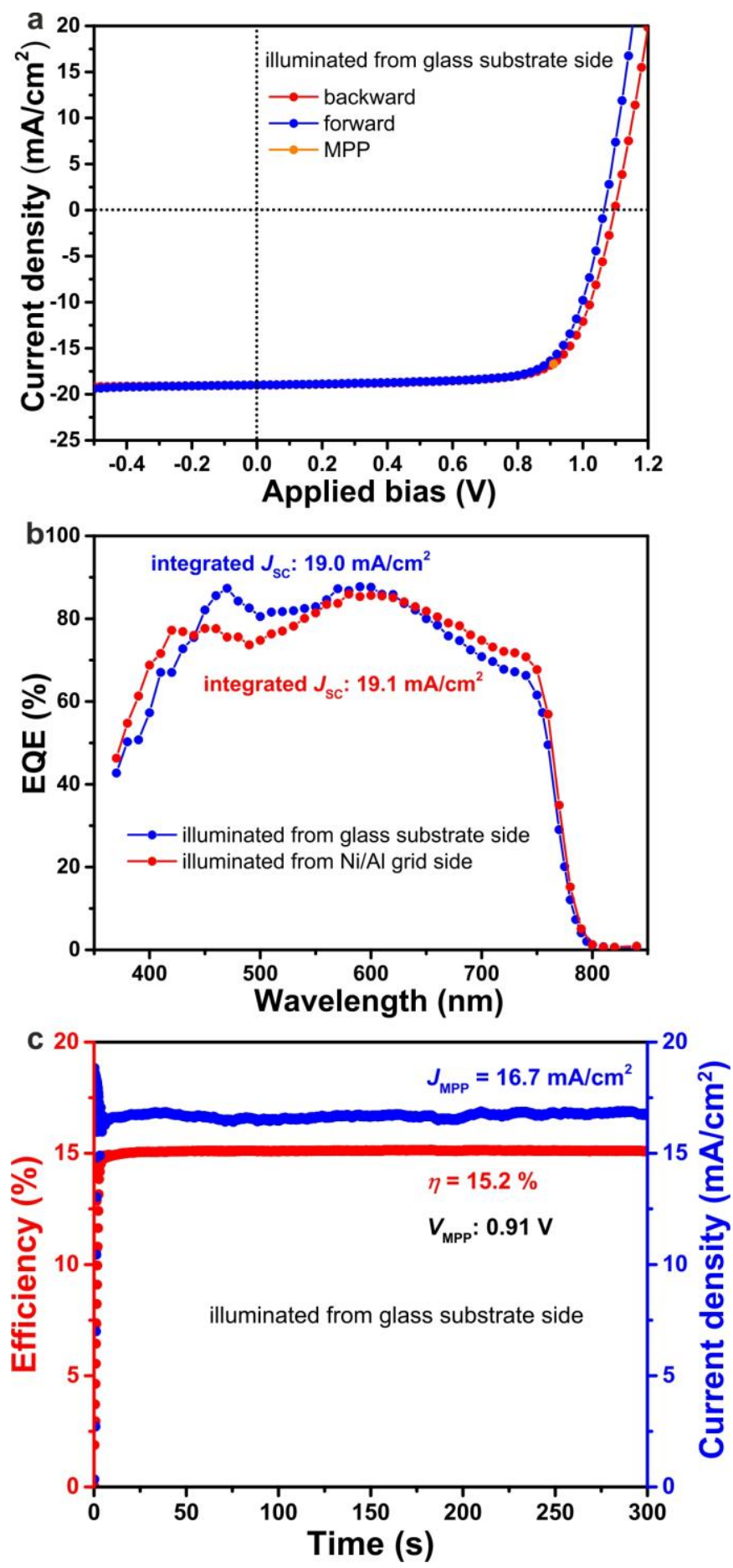

Supplementary Figure 3. Photovoltaic performance of device illuminated from glass side. a, b, c, The $J$ - $V$ curves (a), EQE spectra (b), and steady state output (c) of the best cell (shown in Fig. 3) illuminated from the glass side. It is to be noted that the measurements were performed in the light soaked state. 

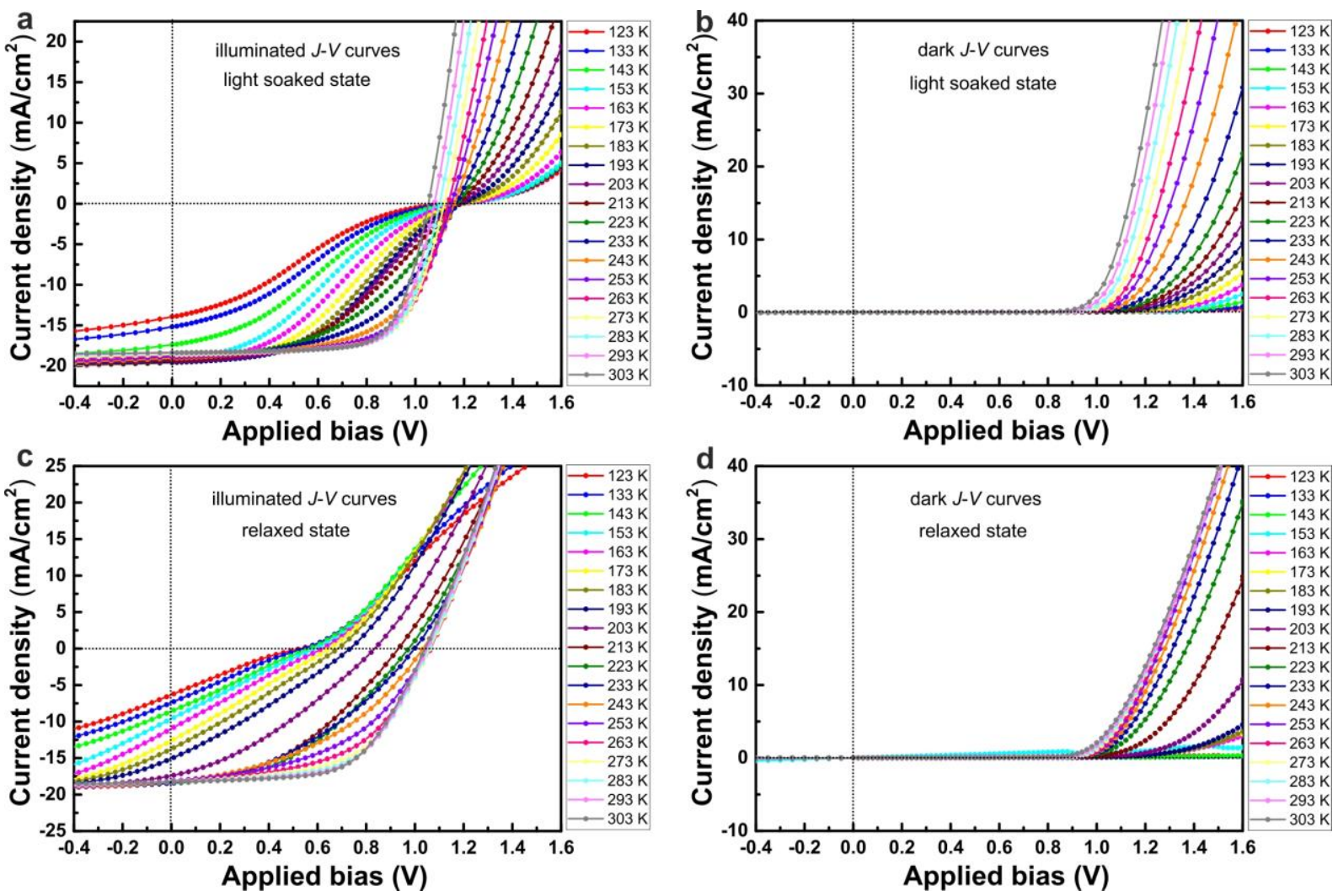

Supplementary Figure 4. Temperature dependent $J$ - $V$ characteristics. a, b, The illuminated and dark temperature dependent $J-V$ curves in light soaked state. c, d, The illuminated and dark temperature dependent $J-V$ curves in relaxed state. 
a
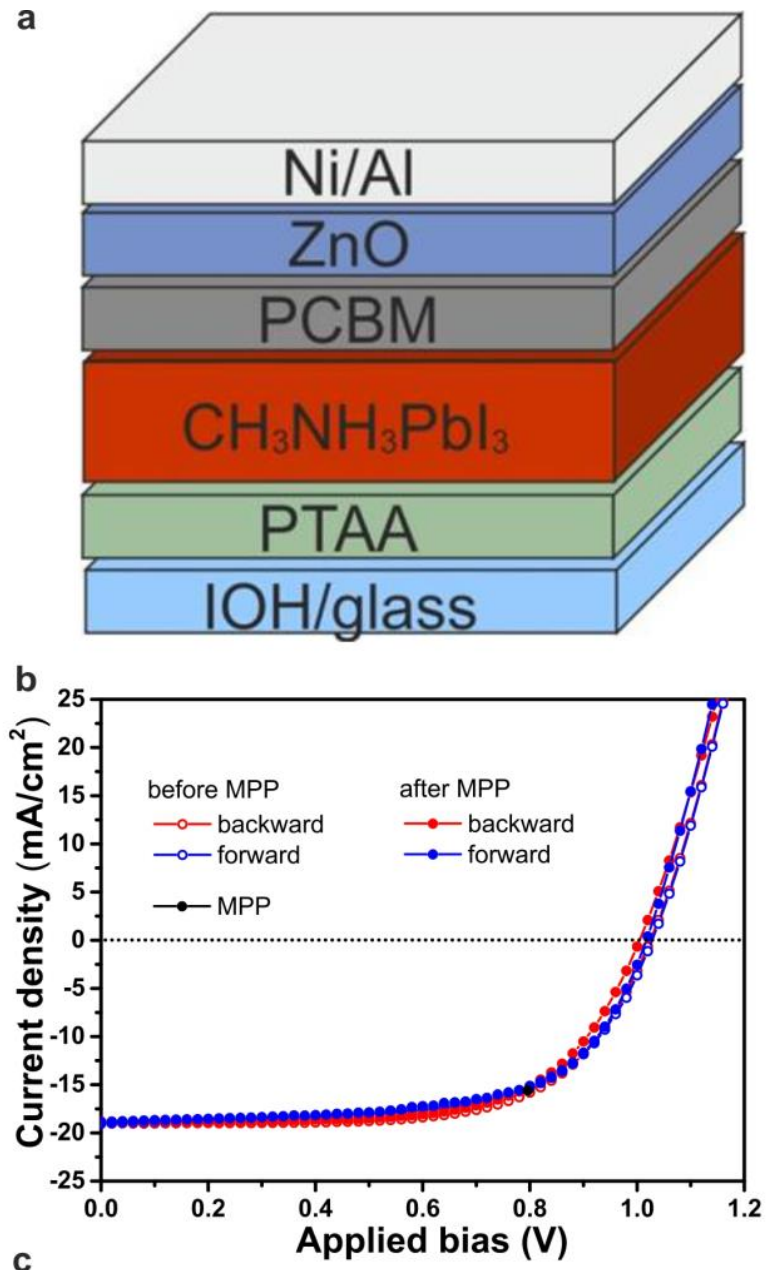

C

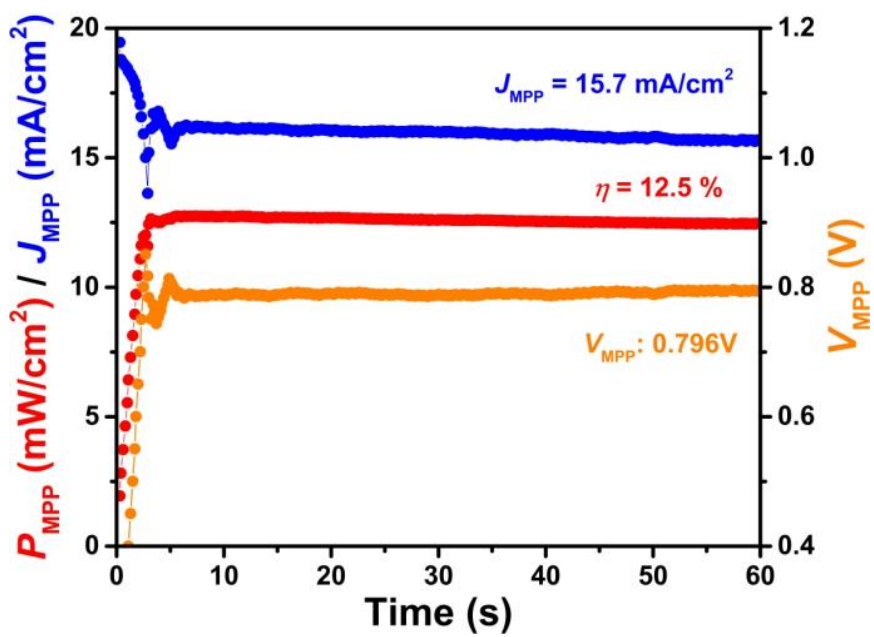

Supplementary Figure 5. Planar perovskite solar cell with RF-magnetron sputtered

ZnO. a, The schematic device structure of perovskite solar cell with sputtered $\mathrm{ZnO}$ (substitute for solution-processed $\mathrm{ZnO}$ nanoparticles). b, c, The $J$ - $V$ curves (b) and steady-state output (c) for device with sputtered $\mathrm{ZnO}$ before and after MPP measurement. The negligible change in $J-V$ curves and short time to reach steady state indicate the absence of light soaking effect in device with sputtered $\mathrm{ZnO}$ electron transporting layer. Intrinsic $\mathrm{ZnO}$ films were deposited in a high vacuum sputtering system (AJA Intl.) by RF-magnetron sputtering of ceramic $\mathrm{ZnO}$ target at an applied sputter power density of $2.4 \mathrm{~W} / \mathrm{cm}^{2}$ without intentional heating of the substrate. The reactive atmosphere consisted of a gas mixture of $\mathrm{Ar}$ and $\mathrm{Ar} / \mathrm{O}_{2}$ at a total pressure of $0.16 \mathrm{~Pa}$. The deposition time is $25 \mathrm{~min}$, which yields $30 \mathrm{~nm}$ thick $\mathrm{ZnO}$ films. 

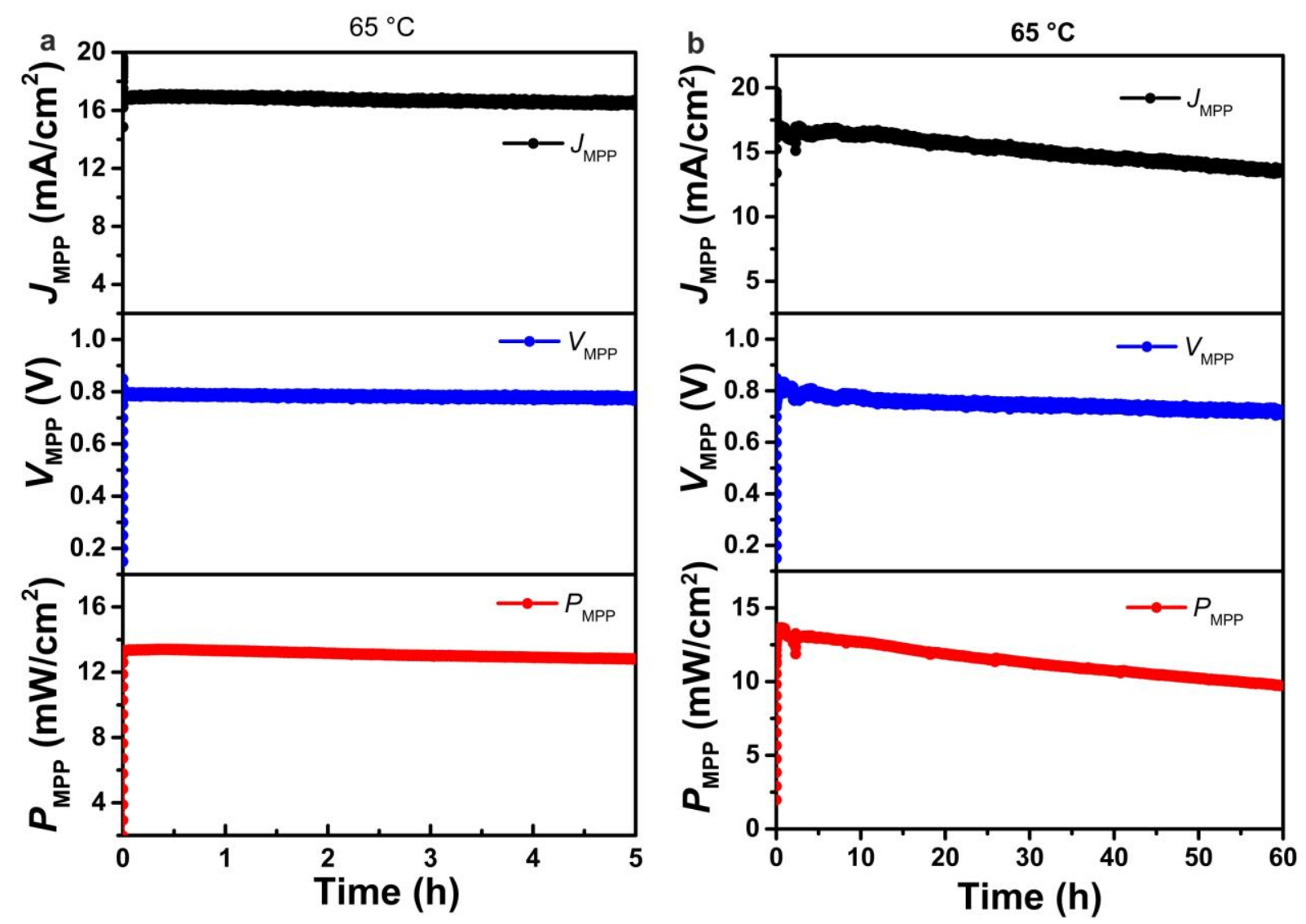

Supplementary Figure 6. Device stability at $65^{\circ} \mathrm{C}$ under constant one-sun illumination. a, b, The maximum power point measurements for the substrate configuration perovskite solar cell aging at $65^{\circ} \mathrm{C}$ substrate temperature for 5 hours (a) and 60 hours (b). The device maintained above $70 \%$ of its original value after more than 60 hours aging at $65^{\circ} \mathrm{C}$. The devices were not encapsulated and the measurements were done in cryostat chamber under vacuum (base pressure $<5 \times 10^{-4}$ mbar) with full area one-sun illumination. A halogen lamp is used as light source and the intensity is adjusted to match $J_{\mathrm{SC}}$ for one sun illumination. A 3 mm fluorine-doped tin oxide (FTO, TEC-15) coated glass was put in front of the light source to minimize the heating effect from infrared light. 

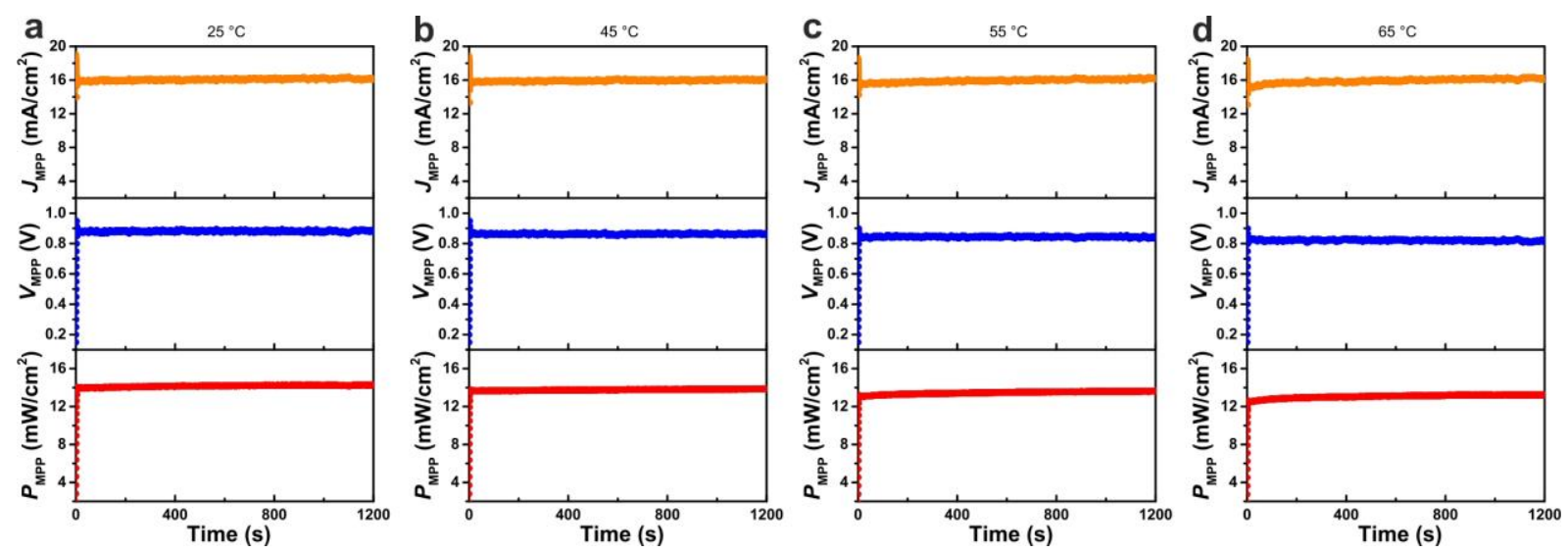

Supplementary Figure 7. Steady-state output of substrate configuration perovskite solar cells at different temperature. The cell was not encapsulated and the measurements were done under vacuum. The device was light soaked for more than 1 hour at room temperature to reach steady-state before each measurement. The measurements were done after the temperature was stabilized at desired temperature point. 


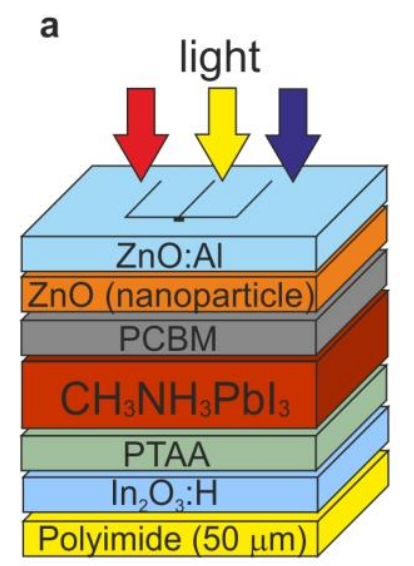

b

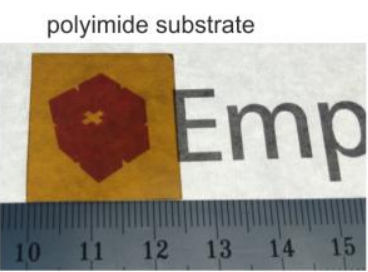

perovskite solar cells grown on polyimide substrate
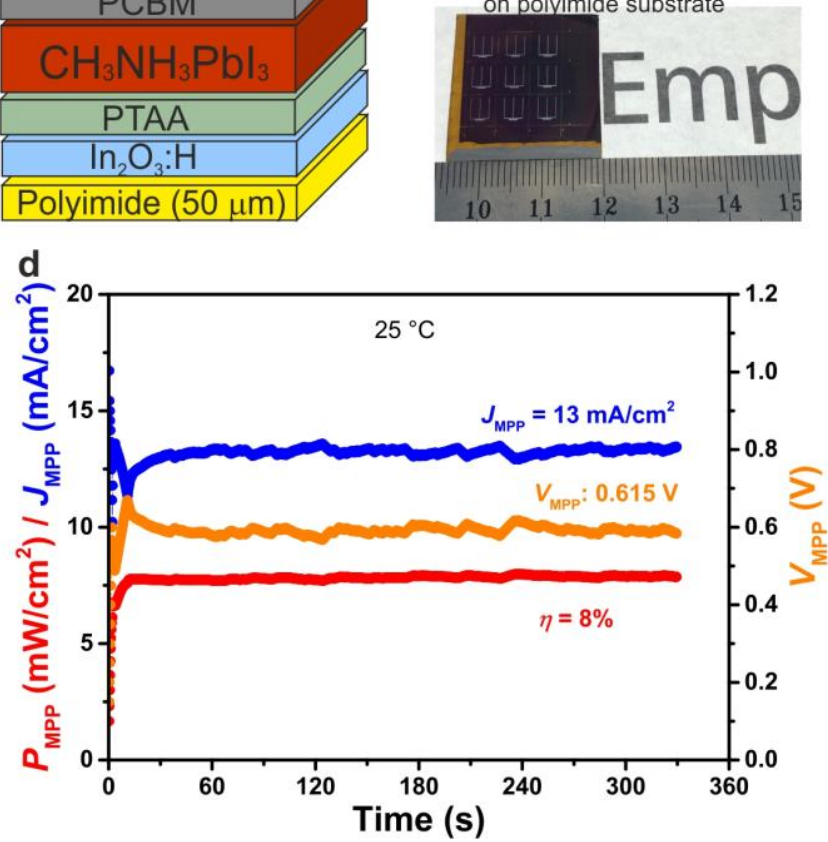

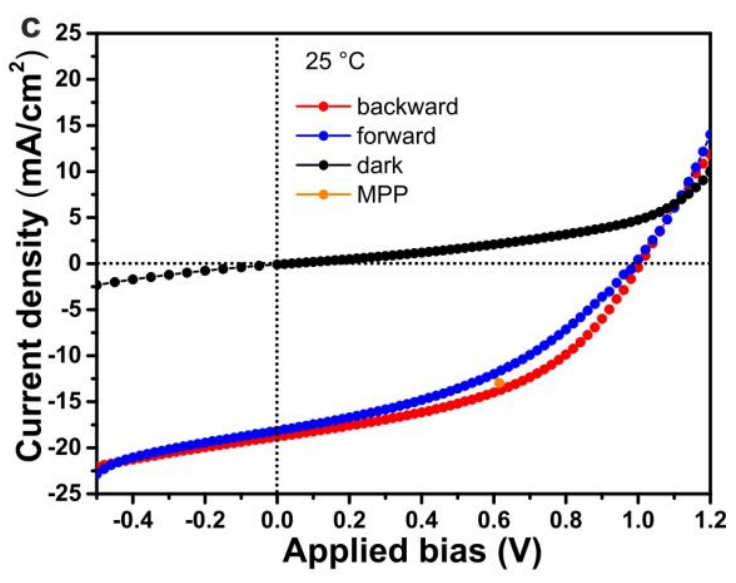

e

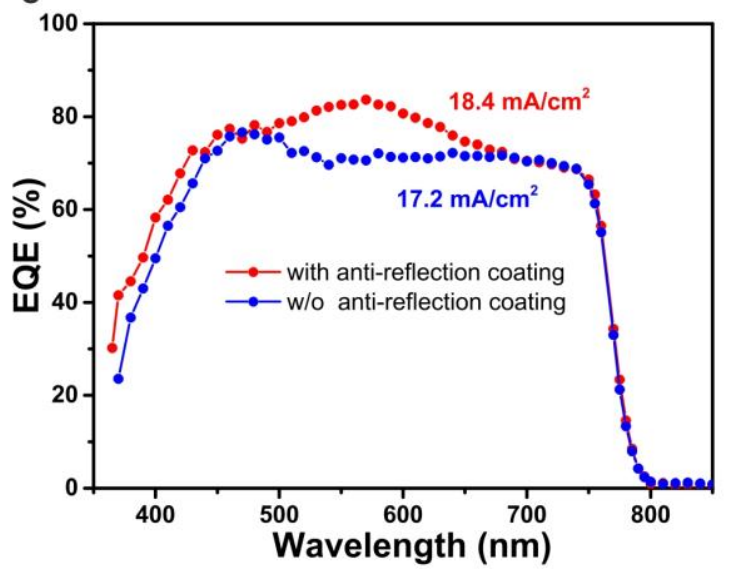

Supplementary Figure 8. Planar perovskite solar cells grown on flexible polyimide substrate. a, The schematic device structure of the flexible perovskite solar cell. b, Photograph of $50 \mu \mathrm{m}$ polyimide substrate (upper one) and with perovskite solar cell grown on top of it (lower one). c, The $J-V$ curves of flexible perovskite solar cells measured under standard test condition (STC: $25^{\circ} \mathrm{C}, \mathrm{AM} 1.5 \mathrm{G}, 1000 \mathrm{~W} \mathrm{~m}^{-2}$ ). Small degree of hysteresis is observed between forward and backward scan. d. Steady state output at maximum power point (MPP) under STC. e, The EQE spectra of corresponding cell measured with and without $105 \mathrm{~nm}$ antireflection coating. The integrated $J_{\mathrm{SC}}$ from EQE agrees well with value extracted from $J-V$ scan. The cell area is $0.293 \mathrm{~cm}^{2}$ defined by mechanica scribing down to back $\operatorname{In}_{2} \mathrm{O}_{3}: \mathrm{H}$ and anti-reflection coating is applied in this case. The device was not encapsulated, and all the measurments are conducted in ambient air with relative humidity of $50 \%$. 

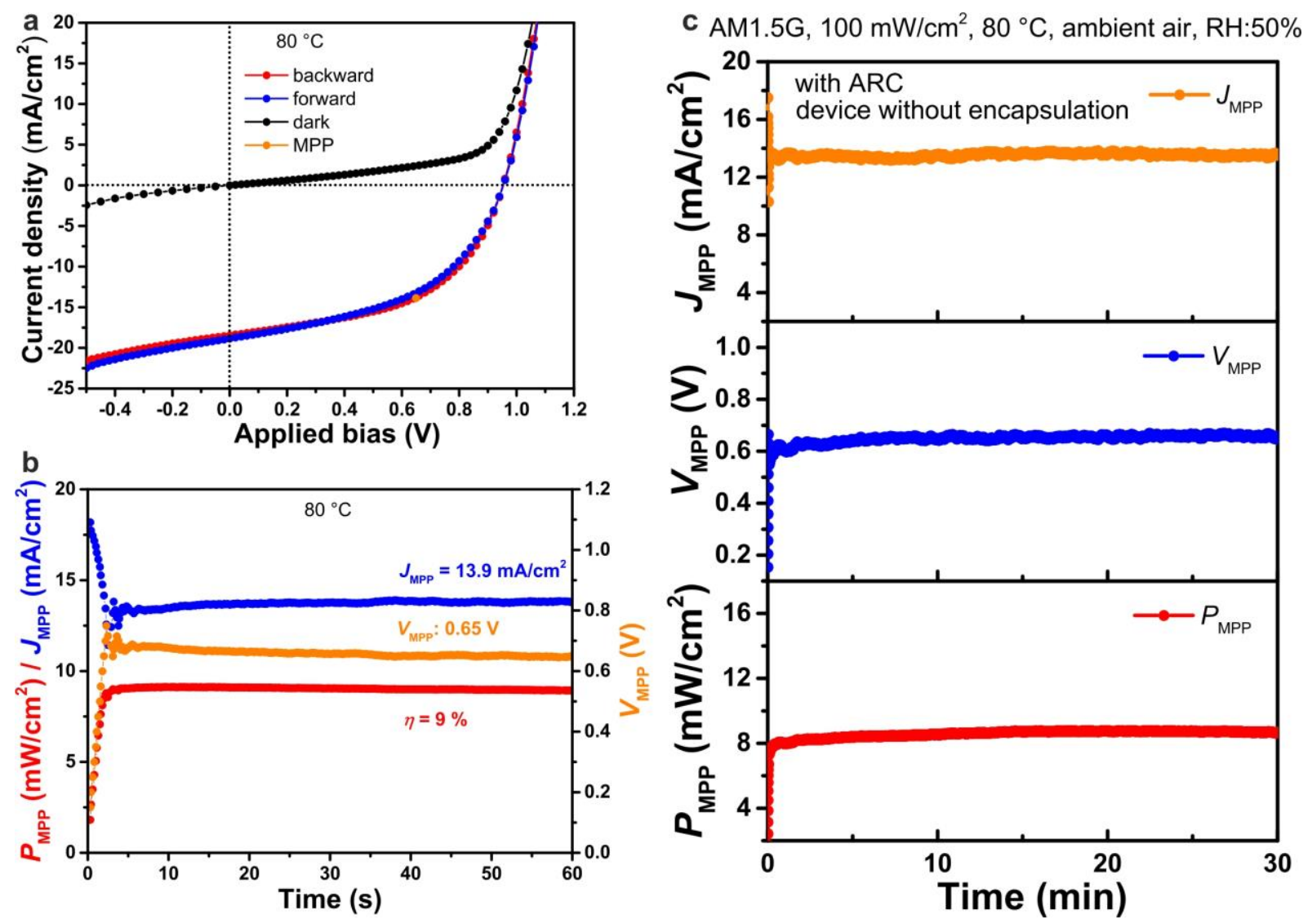

Supplementary Figure 9. Device performance of flexible perovskite solar cells at elevated temperature $\left(80^{\circ} \mathbf{C}\right)$. a, The $J-V$ curves of flexible perovskite solar cell (same cell as shown in Supplementary Figure 8) measured at $80^{\circ} \mathrm{C}$ under simulated AM1.5G one-sun illumination. The hysteresis almost disappeared at high temperature and efficiency improved as compared to value measured at $25^{\circ} \mathrm{C}$. b. Steady state output at maximum power point (MPP) measured at $80^{\circ} \mathrm{C}$. c. MPP measurement for $30 \mathrm{~min}$ at $80^{\circ} \mathrm{C}$. The device remains stable under continuous illumination at elevated temperature. The device was not encapsulated, and all the measurments are conducted in ambient air with relative humidity of $50 \%$. 


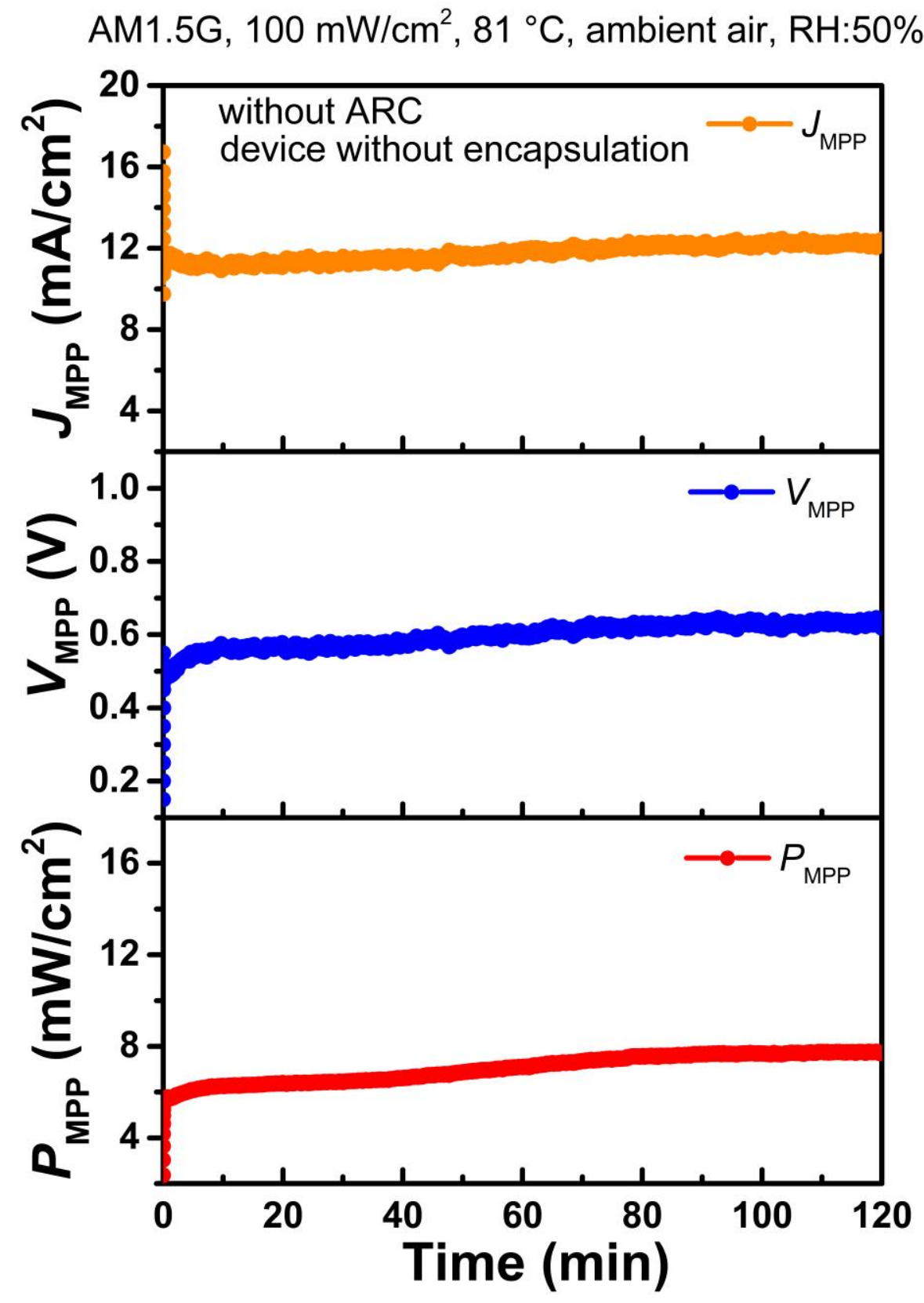

Supplementary Figure 10. Performance stability of flexible perovskite solar cells measured at elevated temperature $\left(81^{\circ} \mathbf{C}\right)$. The measured cell was the same as shown in Supplementary Figure 8-9, but without anti-reflection coating. The cell (without encapsulation) was kept at MPP under continuous simulated AM1.5G one-sun illumination at $81^{\circ} \mathrm{C}$. All the measurments were peformed in ambient air with relative humidity of $50 \%$. The device did not show sign of degradation. The steady state efficiency is higher than value obtained at $25^{\circ} \mathrm{C}$. 


\begin{tabular}{|l|c|c|c|}
\hline & $\boldsymbol{R}_{\mathbf{0}}\left(\mathbf{\Omega} \mathbf{c m}^{2}\right)$ & $\boldsymbol{\theta}_{\mathrm{B}} \mathbf{( \mathbf { m e V } )}$ & $\boldsymbol{c}\left(\mathbf{\Omega} \mathbf{c m}^{\mathbf{2}}\right)$ \\
\hline Relaxed state & 9.2 & 165 & $3.6 \mathrm{e}-4$ \\
\hline Light soaked state & 2.3 & 257 & $2.2 \mathrm{e}-5$ \\
\hline
\end{tabular}

Supplementary Table 1: Fitting results for the temperature dependent series resistance presented in Fig. 5c. 